\title{
The Preparedness of the Faculty Members of Iran University of Medical Sciences for the Training of International Students
}

\author{
Hamid Peyrovi ${ }^{1}$, Tahereh Najafi Ghezeljeh ${ }^{2}$
}

\begin{abstract}
Background \& Aims: Internationalization refers to the process of integrating an international and intercultural dimension into the teaching, research, and service functions of the institution. The internationalization of education emphasizes the process of including the international dimension in all aspects of education, and its main objective is to expand knowledge, abilities, attitudes, and values that are recognized at the international level. Focusing on professors as the main component of the internationalization process is vital, and their attitudes, beliefs, experiences, and levels of engagement are related to their participation in the internationalization process. One of the basic pillars of the process of internationalization of medical education is the assessment of readiness to participate in the international education market. The data obtained by this assessment is a basis for determining policies and directing academic planning. Given the growing emphasis on attracting international students and the moral responsibility of schools and departments in providing and facilitating conditions, the present study aimed to determine the preparedness of professors in educational departments of Iran University of Medical Sciences to train international students.
\end{abstract}

Materials \& Methods: This descriptive, cross-sectional study was performed in nine schools and 99 educational departments of Iran University of Medical Sciences in 2018-2019. The subjects were selected by the voluntary method from all professors of the university $(n=900)$. In total, 378 professors filled the questionnaires. Data were collected through self-report, and research tools included a researcher-made questionnaire based on the professors' attitudes and abilities to train international students. The questionnaires were distributed in various groups in person. Due to the low participation of members and the problems related to access to some people, the questionnaire was subsequently emailed to the professors five times. The questionnaire contained items related to assessing the attitude of professors (14 items) and items related to assessing the ability of professors ( 7 items) in the form of self-report. In addition, a general question (regardless of the level of capability in the field of international student education, are you willing to cooperate in this field? Explain the causes?) was asked, and data analysis was performed in SPSS version 16 using descriptive and inferential statistics, analysis of variance, Scheffe test, independent t-test, Fisher's exact test, and Chi-square. Moreover, the open question related to the reasons for the willingness/unwillingness to cooperate in international student education was analyzed using the qualitative content analysis method.

Results: In this study, the mean age of the participants was $47.08 \pm 8.04$ years. In addition, the majority of the participants were female $(52.1 \%)$ and had a specialized $\mathrm{PhD}$ or $\mathrm{PhD}(44.2 \%)$ and had the academic rank of assistant professor $(54.0 \%)$. About $42.9 \%$ of the participants had previous experience of training international students and mean teaching experience to foreign students of $4.09 \pm 4.06$ years. Furthermore, $28.8 \%$ of the subjects had an experience of educational mission or studying abroad with a mean education experience of $1.01 \pm 2.54$ years. Most of the participants had the experience of living abroad (63.8\%) and the majority of the participants had an English Language Certificate (62.2\%). The mean score of attitude and abilities of the subjects in training international students was relatively favorable and reported to be $53.14 \pm 8.65$ and $23.32 \pm 5.17$, respectively. According to the results, there was a direct, weak, and significant relationship between work experience and ability in the field of international student education $(\mathrm{P}=0.005)$. In people with more work experience, the tendency to cooperate in international student training was higher $(\mathrm{P}=0.038)$ and professors with international student training experience expressed more ability in this field. Moreover, there was a direct, weak, and significant association between the duration of international student training and competence in this field $(\mathrm{P}=0.025)$. The participants with a history of educational mission or study abroad as well as living abroad reported a positive attitude and ability in educating international students. On the other hand, no significant relationship was observed between the duration of study abroad with the attitude and ability to train an international student and the desire to train an

\footnotetext{
1. Professor, Nursing Care Research Center, Iran University of Medical Sciences, Tehran, Iran

2. Associate Professor, Nursing Care Research Center, Iran University of Medical Sciences, Tehran, Iran (Corresponding author) Tel: $\mathbf{0 2 1 4 3 6 5 1 0 0 0}$ Email: najafi.t@iums.ac.ir
} 
international student $(\mathrm{P}=0.00)$. Regarding English language proficiency, those with an English Language Certificate had a higher ability to train international students $(\mathrm{P}=0.022)$. In terms of gender, men had a more positive and empowered attitude towards foreign student education, although women were more willing than men to cooperate in internationalization. According to the results, $61.4 \%$ of the subjects were reluctant to cooperate in educating international students. Reasons related to an unwillingness to cooperate in international student education were divided into two categories of individual and academic, and causes related to willingness to cooperate were divided into four categories of individual and professional, educational group, university, and country.

Conclusion: According to the results of the study, the professors expressed a relatively favorable attitude and ability in the field of international student education. A review of the literature revealed that professors' behavior is affected by two individual and social knowledge factors. In this regard, individual factors were demographic characteristics, job characteristics, and professions of professors and the social knowledge was recognized as professors' perception of the values and expectations of the educational institution, rewards, and teachers' selflearning that shape the behavior of faculty members. Some of the causes of professors' willingness to participate in training foreign students were promoting individual and professional competence, increasing competence in English, educational methods, gaining experience, opportunities for scientific exchange, contributing to individual dynamism, emerging individual competence and familiarity with other cultures. On the other hand, individual causes for unwillingness to cooperate in foreign student education were lack of financial benefits, job motivation and security, lack of English language proficiency, multiple job descriptions, lack of time, high workload, and foreign student education as increasing workload and stress. One of the most important mechanisms in the internationalization process is to prepare professors in the internationalization process. Therefore, the necessary infrastructures must be provided in universities to improve internationalization. It is suggested that motivational and empowerment programs be designed by university officials to improve professors' attitude and enhance their ability to cooperate in international student education.

Keywords: Internationalization, Attitude, Ability, Professors

\section{Conflict of Interest: No}

How to Cite: Peyrovi H, Najafi Ghezeljeh T. The Preparedness of the Faculty Members of Iran University of Medical Sciences for the Training of International Students. Iran Journal of Nursing. 2020; 32(122):14-29.

Received: 5 Nov 2019

Accepted: 3 Feb 2020 


\title{
آمادكى استادان ّروههاى آموزشى دانشكاه علوم يزشكى ايران در زمينه تربيت دانشجوى بين الملل
}

\author{
حميد ييروى'، طاهره نجفى قزلجه
}

جكيده

زمينه و هدف: يكى از اركان اساسى فرآيند بين المللىسازى آموزش يزشكى ارزيابى آمادكى جهت حضور در بازار آموزش بين المللى است. دادههاى

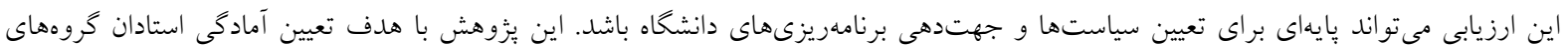

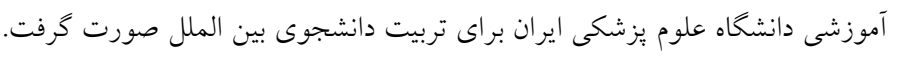

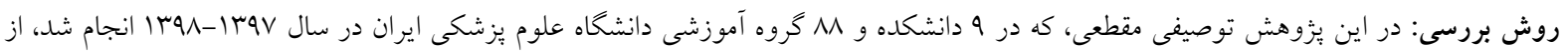

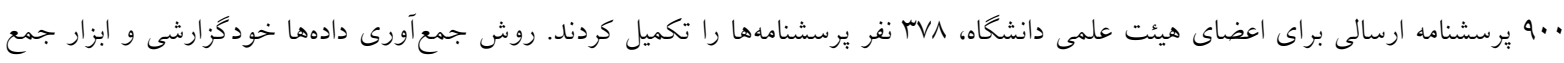

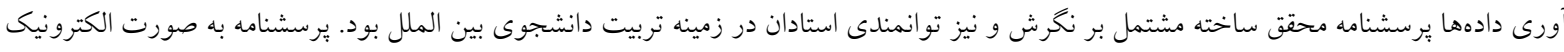

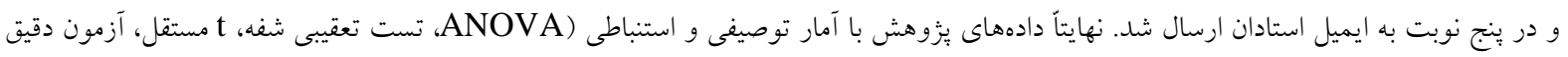

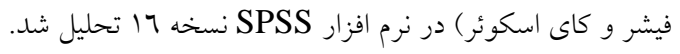

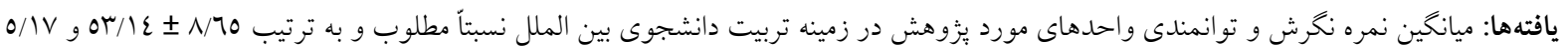

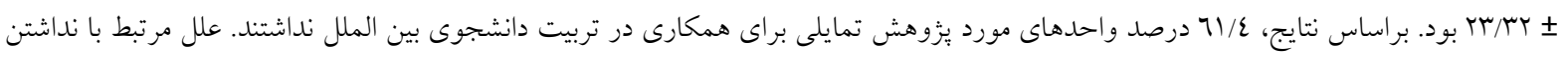

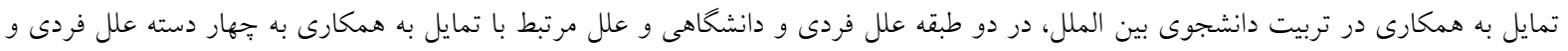

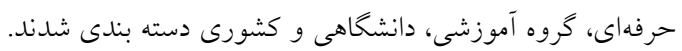
نتيجه گيرى كلى: براساس يافتها، ضرورى است بستر و زيرساختهاى لازم در جهت بين المللى سازى دانشخاه فراهم شود و در راستاى بهبود نخرش و ارتقاى توانمندى استادان براى همكارى در تربيت دانشجوى بين الملل برنامههاى انخيزشى و توانمندسازى توسط مسئولين دانشخاه طر احى گردند. كليد وازهها: بين المللمىازى، نخرش، توانمندى، استادان 
توسعه دهد (9) Evans در بررسى تجربه دانشجويان يرستارى بين الملل و استادان راهنماى آنها در بريتانيا

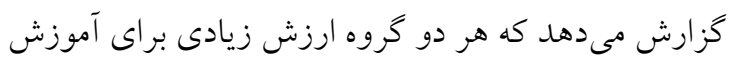

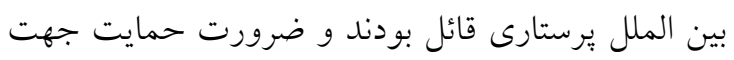

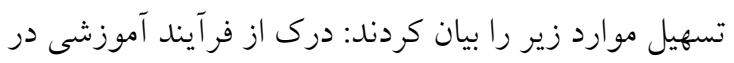
مقاطع تحصيلات تكميلى، يادكيرى زبان دوم، فعاليت در

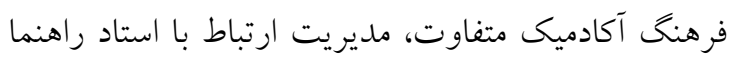

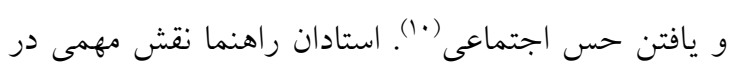
رفع نيازهاى مختلف دانشجويان بين الملل داشته و ورنمي مطالعات بر اهميت گسترده نمودن نقش استادان و حمايت مؤسسات آموزشى از آنها براى ايفاى اين نقش تأكيد

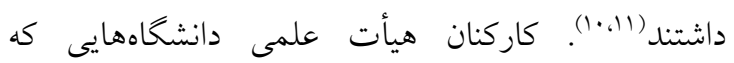
دانشجوى بين المللى تربيت مى كنند لازم است راهبردهاى

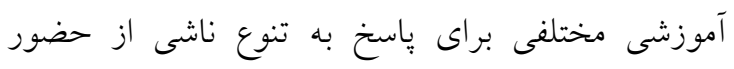

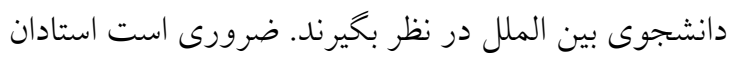

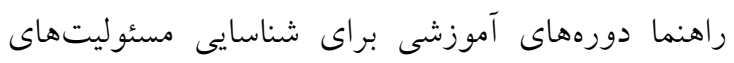

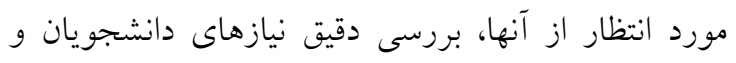

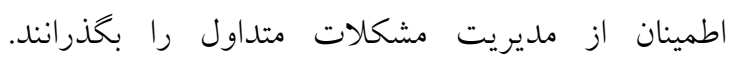
انديشيدن تدابيرى جهت جبر ان اقدامات استادان راهنما در

$$
\text { دانشعاهها نيز اهميت دارد (·). }
$$

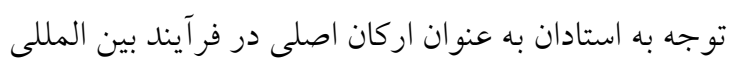

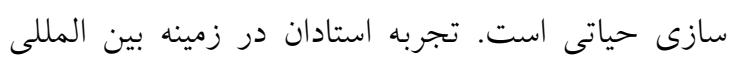

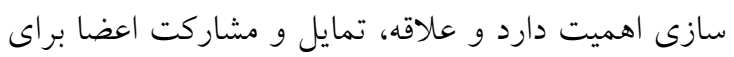

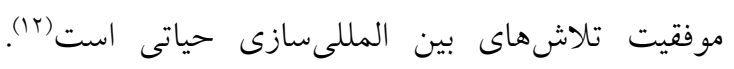

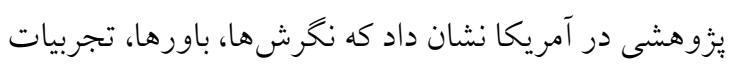

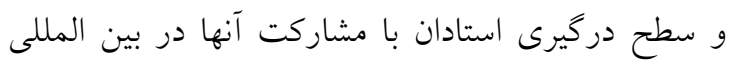

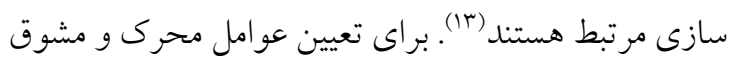

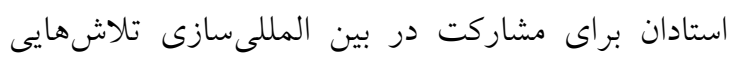

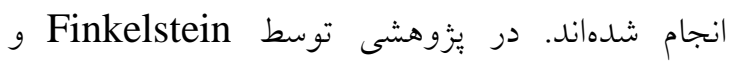

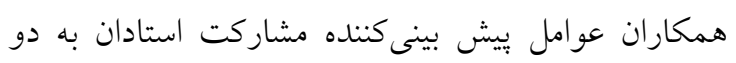

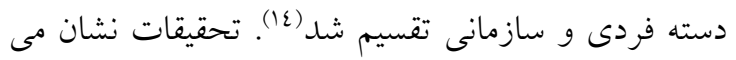

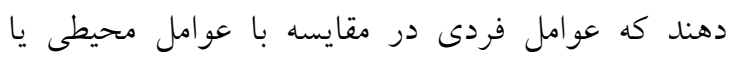
سازمانى توضيح دهنده قوى ترى در عملكرد اعضاى هيئت

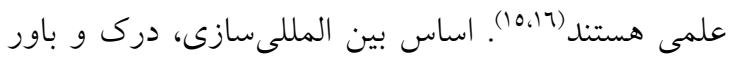

\section{مقلدمه}

با جهانى شدن مسائل مربوط به سلامت، حمايت از

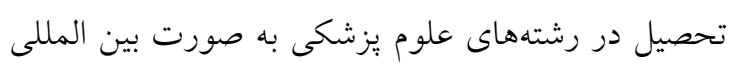

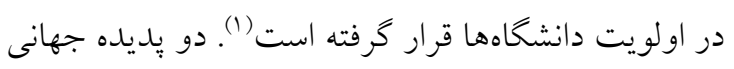

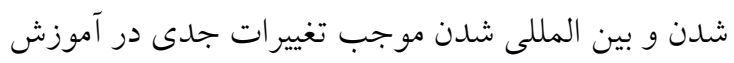
عالى شدهاند. جهانى شدن و بين المللى سازى با هم مرتبط

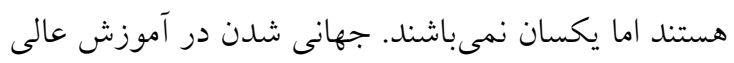
فرآيندى است كه به موجب آن يكى دانشكده يا دانشگاه

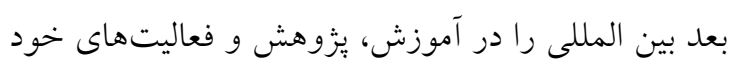

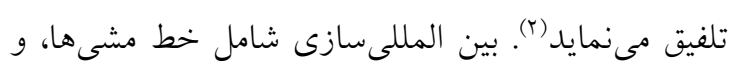

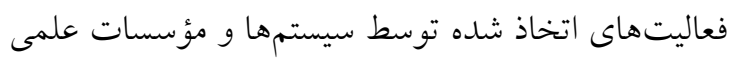

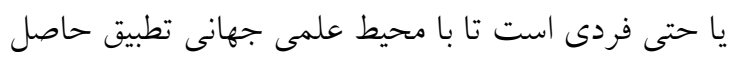

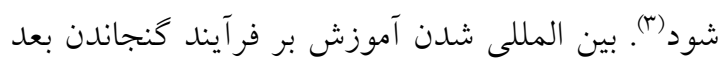

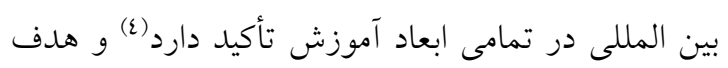

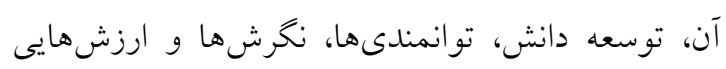

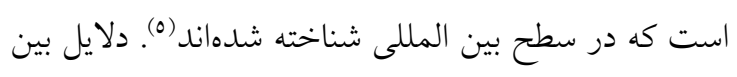

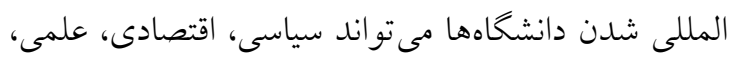

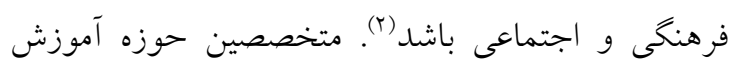

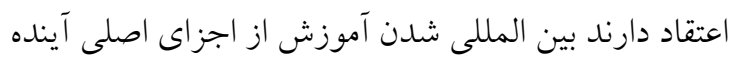

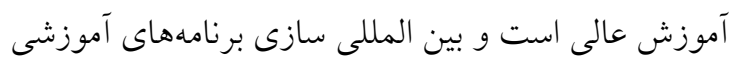

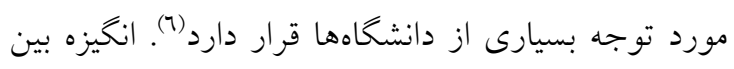

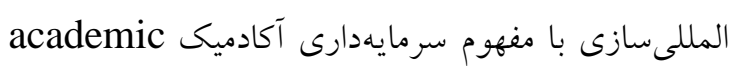

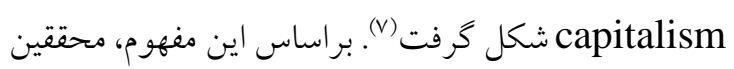
و مديران دانشخاه وادار به شركت در محيط به طور فزاينده رقابتى براى جلب سرمايه از هر نوع شدهاند (1).

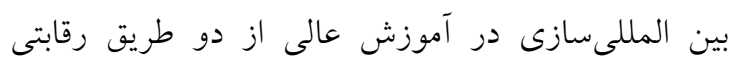

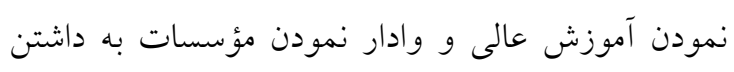

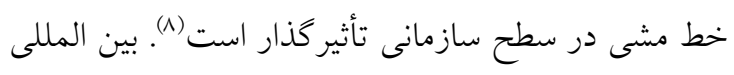

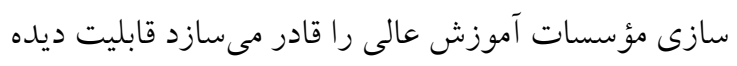

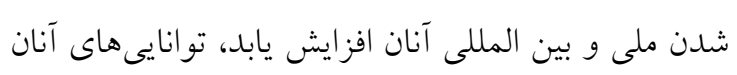

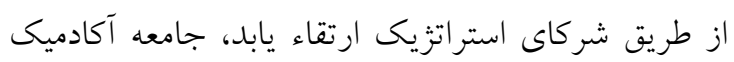
جهت انجام فعاليتهاى تجارى بزرگ شود، منابع خردمند داخلى بسيج شوند، ييامدهاى يادگيرى مهم را به تجربه

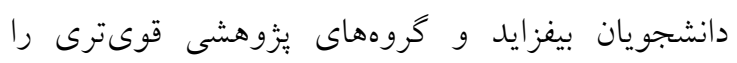




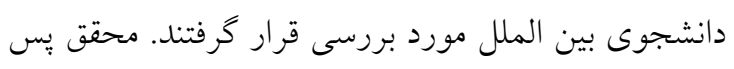

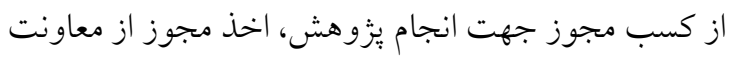

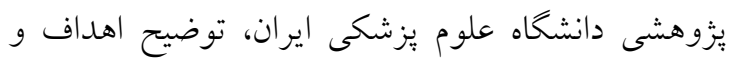

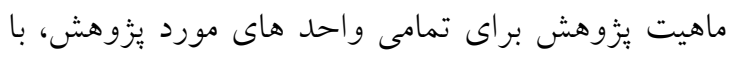

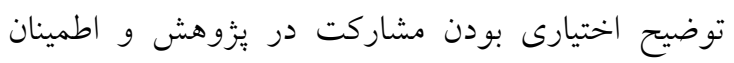

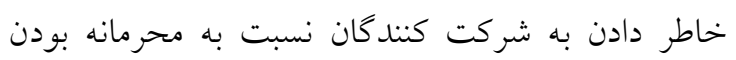

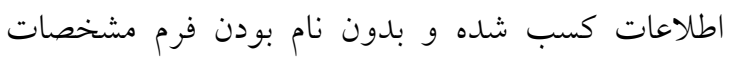

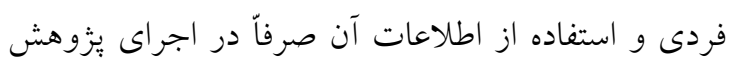

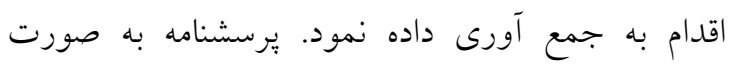

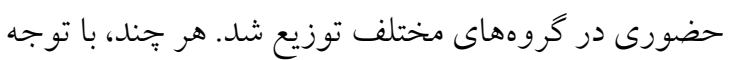

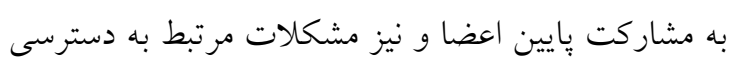

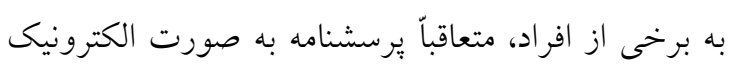
در google form طراحى شده و در ينج نوبت به ايميل

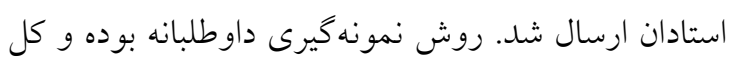

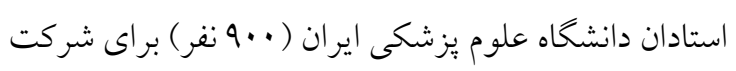
در يززوهش دعوت شدند.

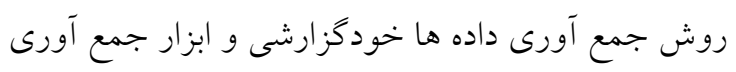

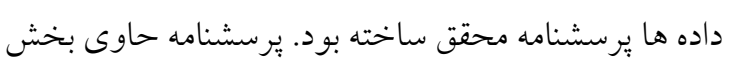

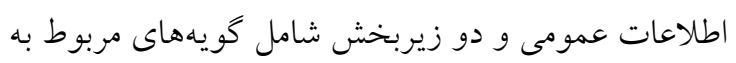

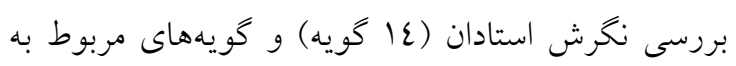

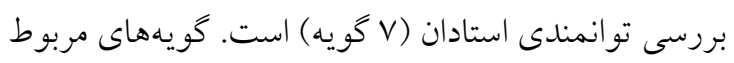
به سنجش نكرش در مقياس ينج قسمتى ليكرت از "كاملاً

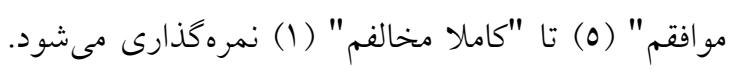

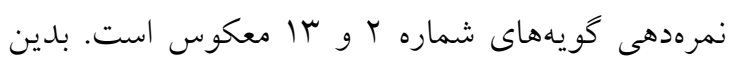
ترتيب دامنه نمره نخرش استادان نسبت به تربيت دانشجوى نداره

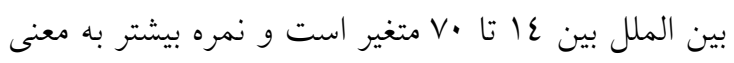

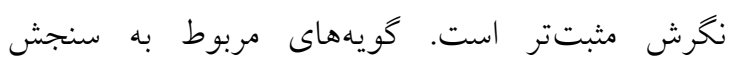

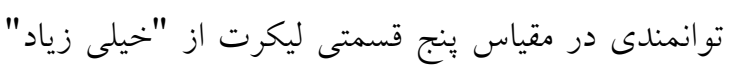

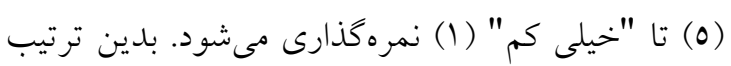
دامنه نمره توانمندى اعضاء در زمينه تربيت دانشجوى بين لمرهي

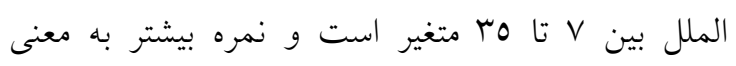

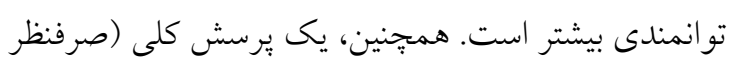

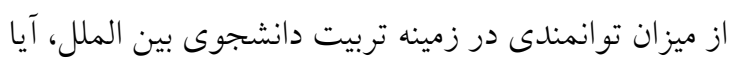

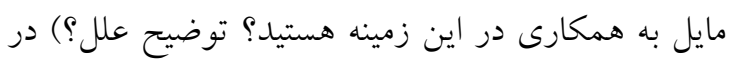

توانايى يا خودكارآمدى استادان در ابعاد بين المللى است.

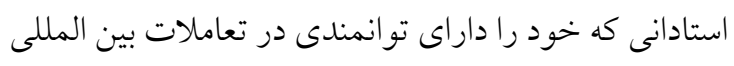

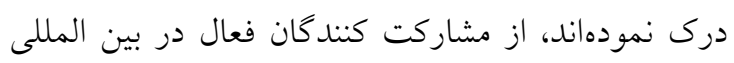
سازى هستند. اين افراد خودارزيابى مثبتى از مهارتهايشان

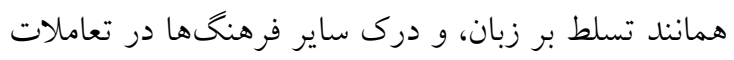

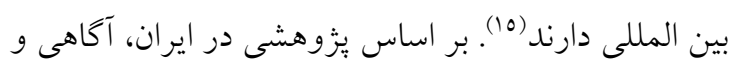

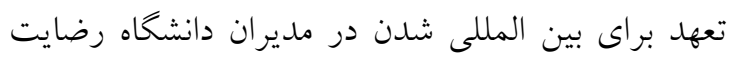
بخش بود. هر جند اين يافته با وضعيت مطلوب فاصله

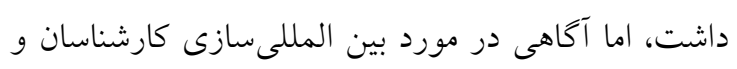

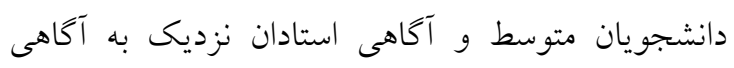
مديران بود اما تا سطح مطلوب فاصله داشتند و نيز تعهد استادان تا وضعيت مطلوب فاصله زيادى داشت (IV).

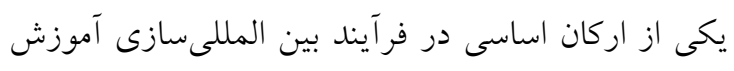

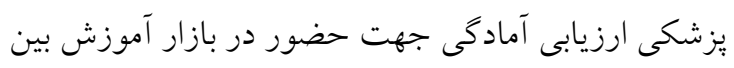

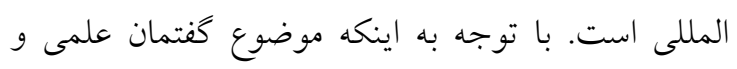
فرهنگى كشور در عرصه جهانى در اسناد بالادستى همانند

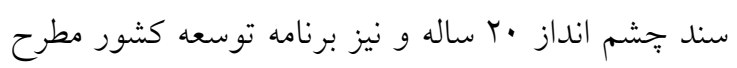

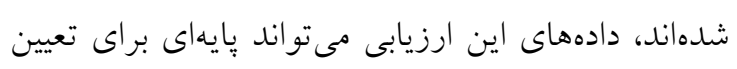

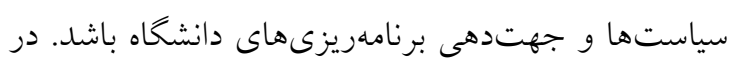

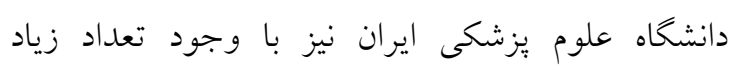

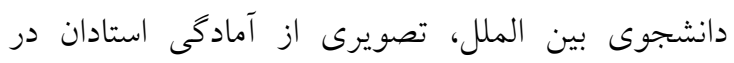

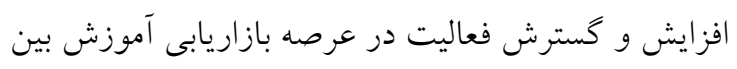

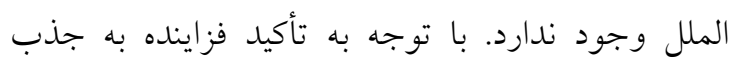

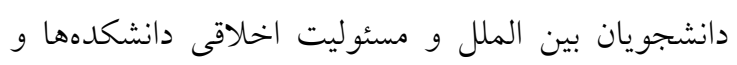

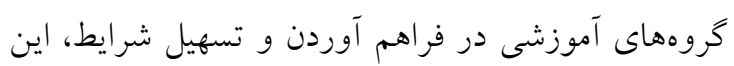

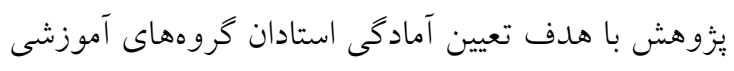

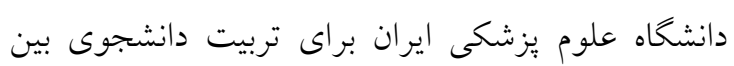
الملل صورت گرفت.

\section{روش بررسى}

در اين يُزوهش توصيفى مقطعى، استادان خروههاى

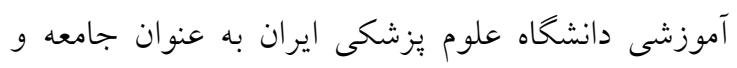

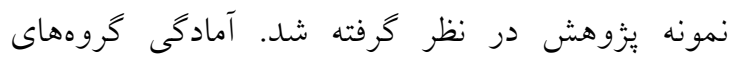

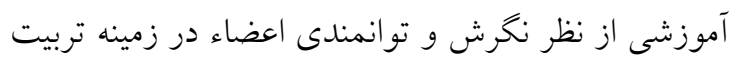


از بين حدود .9 عضو هيأت علمى دانشخاه، MVN عضو هيأت علمى در يُزوهش شركت نموده و وِرسشنامهها

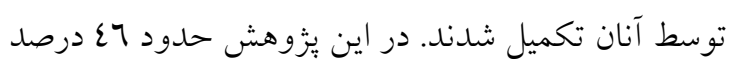

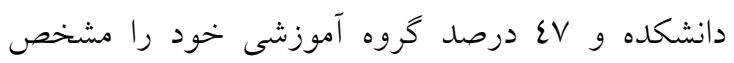

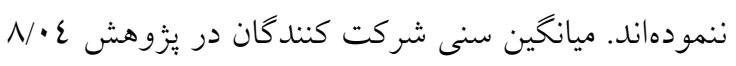

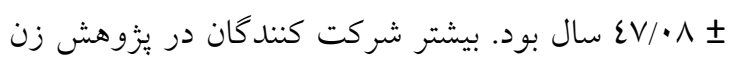

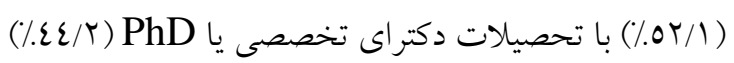

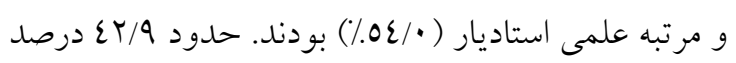
واحدهاى مورد يُزوهش سابقه تربيت دانشجوى بين الملل

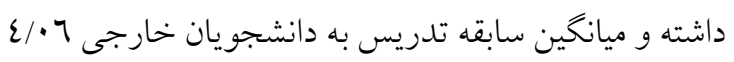

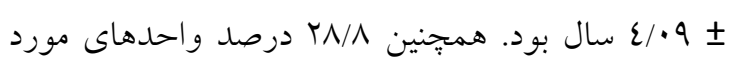

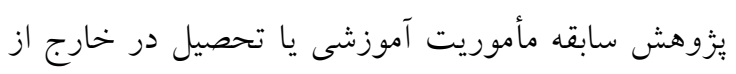

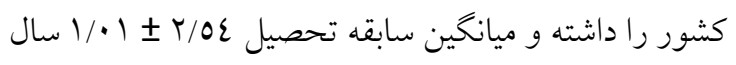

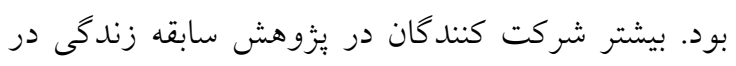

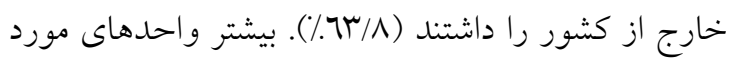

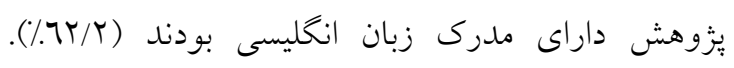
شاخص هاى عددى نخرش و توانمندى استادان در زمينه

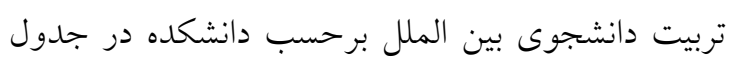

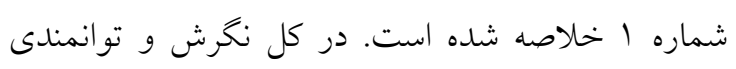

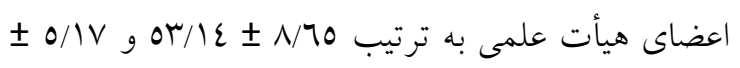

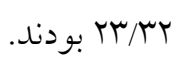

زمينه تمايل اعضاء گروه براى تربيت دانشجوى بين الملل

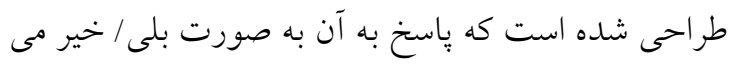

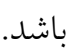
جهت تعيين روايى ابزار كردآورى دادهها، از روايى محتوى باتئل

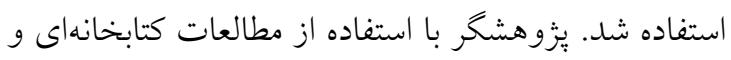

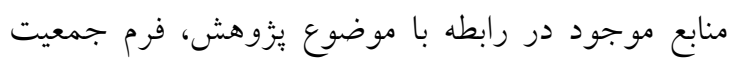

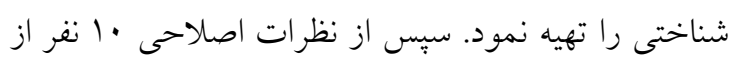

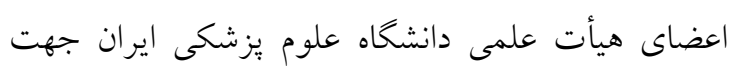

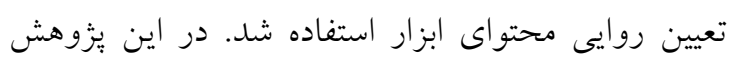

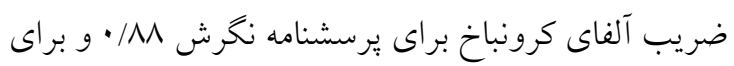

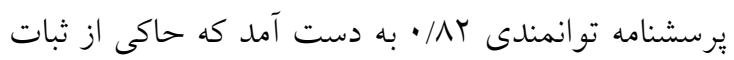
درونى يرسشنامهها است. دادهها با استفاده از آمار توصيفى و استنباطى (ANOVA)

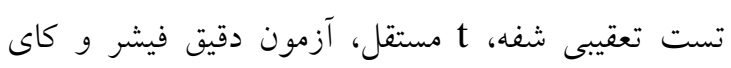

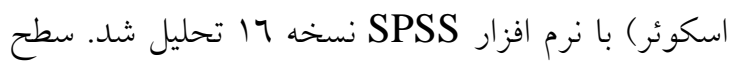
معنى دارى 0 ×٪ در نظر كرفته شد. هم:جنين سئوال باز

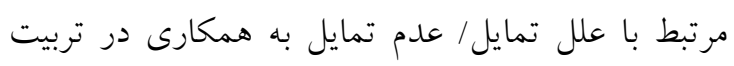

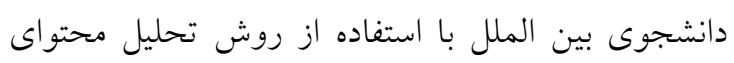
كيفى تحليل شد.

\section{يافتهها}

جدول شماره ا: شاخصهاى عددى نكَرش و توانمندى استادان در زمينه تربيت دانشجوى بين الملل بر حسب دانشكده

\begin{tabular}{|c|c|c|c|}
\hline 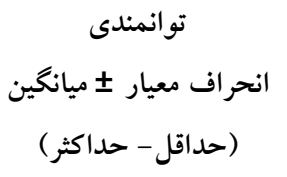 & انحراف معيار 土 ميانگين & (درصد) فراوانى & دانشكده \\
\hline $\begin{array}{c}r \varepsilon / 00 \pm T / 70 \\
(r 0-1 \varepsilon)\end{array}$ & $\begin{array}{c}0 \varepsilon / \cdot r \pm 1 \cdot / M \\
(T V-r \varepsilon)\end{array}$ & $r q(\mid \varepsilon / r)$ & يرستارى و مامايى \\
\hline $\begin{array}{c}r \varepsilon / \cdot 1 \pm \varepsilon / 97 \\
(r 0-1 r)\end{array}$ & $\begin{array}{c}O \varepsilon / N O \pm N / \Lambda r \\
(V \cdot-r V)\end{array}$ & $V_{0}(r T / \Lambda)$ & يزشكى - بالينى \\
\hline $\begin{array}{c}r T / \mu \pm 0 / 7 \varepsilon \\
(r 0-10)\end{array}$ & $\begin{array}{c}o r / \varepsilon \cdot \pm T / q r \\
(\varepsilon r-T V)\end{array}$ & $10(V / 2)$ & يز شكى - علوم يايه \\
\hline $\begin{array}{c}r V / \cdots \pm \varepsilon / 7 . \\
(r 0-10)\end{array}$ & $\begin{array}{c}\Delta T / \varepsilon Y \pm N / \varepsilon r \\
(T V-Y r)\end{array}$ & $Y \Psi(I T / N)$ & بهداشت \\
\hline $\begin{array}{c}r / 0 \Lambda \pm \varepsilon / 0 r \\
(r r-\mid r)\end{array}$ & $\begin{array}{c}o r / \Lambda \cdot \pm 9 / Y) \\
(T V-r r)\end{array}$ & $r V(\mid r / \Gamma)$ & علوم توانبخشى \\
\hline
\end{tabular}




\begin{tabular}{|c|c|c|c|}
\hline $\begin{array}{c}I V / \cdots \pm T / \cdot \\
(11-Y \Psi)\end{array}$ & $\begin{array}{c}00 / r \mu \pm T / 01 \\
(V \cdot-r q)\end{array}$ & $r(1 / 0)$ & طب ايرانى \\
\hline $\begin{array}{c}r O / O V \pm \varepsilon / N T \\
(r 0-19)\end{array}$ & $\begin{array}{c}O V / \cdots \pm 7 / \cdots \\
(70-\varepsilon 0)\end{array}$ & $1 \varepsilon(7 / \Lambda)$ & ي بير ايزشكى \\
\hline $\begin{array}{c}Y Y / l \varepsilon \pm Y / A \cdot \\
(Y V-1 T)\end{array}$ & $\begin{array}{c}01 / 2 r \pm 1 \cdot / 9 V \\
(7 r-r \cdot)\end{array}$ & $V(\Gamma / \varepsilon)$ & علوم رفتارى و سلامت روان \\
\hline $\begin{array}{c}r \Lambda \sim \cdots \pm 0 / 7 T \\
(r Y-r \varepsilon)\end{array}$ & $\begin{array}{c}O Y / \cdots \pm 0 / 77 \\
(07-\{\Lambda)\end{array}$ & $r(\cdot / 9)$ & فناورىهاى نوين يزشكى \\
\hline $\begin{array}{c}r 0 / \cdots \pm 7 / r r \\
(r \varepsilon-17)\end{array}$ & $\begin{array}{c}0 \varepsilon / V O \pm N / T \varepsilon \\
(V \cdot-Y \Psi)\end{array}$ & $7(T / 9)$ & مديريت و اطلاعرسانى سلامت \\
\hline $\begin{array}{c}r \mu / T Y \pm 0 / I V \\
(r O-11)\end{array}$ & $\begin{array}{c}0 r / 1 \varepsilon \pm N / 70 \\
(V \cdot-1 \Lambda)\end{array}$ & $r \cdot \varepsilon(1 \cdots)$ & كل \\
\hline
\end{tabular}

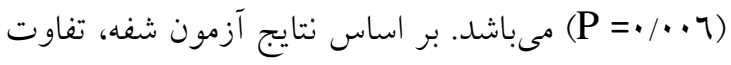
كروههاى مختلف رتبه علمى از نظر توانمندى در مورد

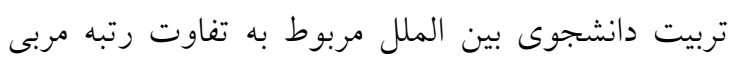

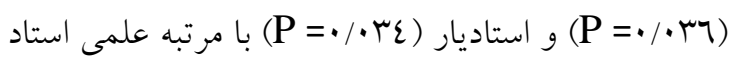

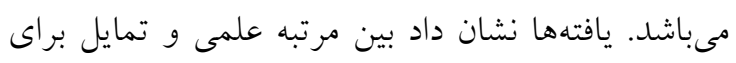
همكارى در تربيت دانشجوى بين الملل ارتباط وجود

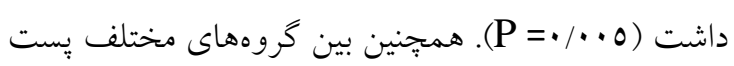

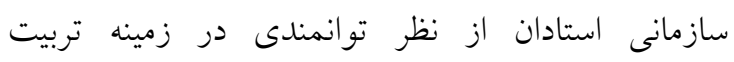

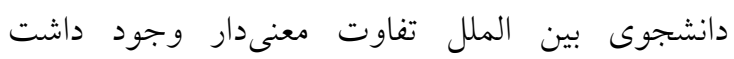

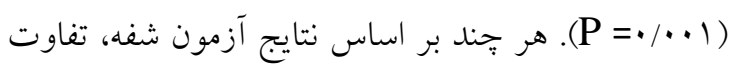

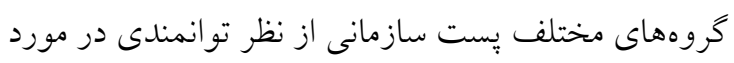

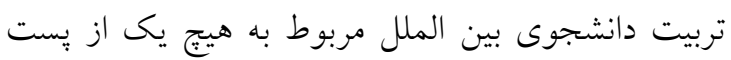

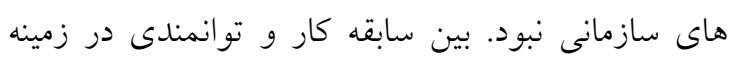

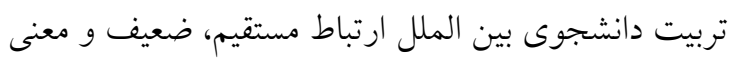

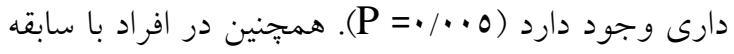
كار بيشتر، تمايل به همكارى براى تربيت دانشجوى بين

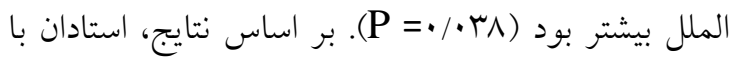

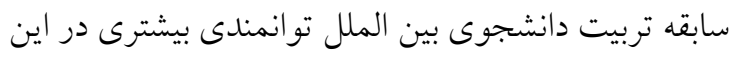

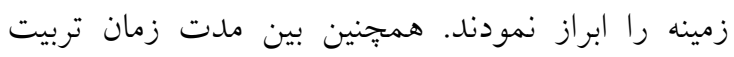
دانشجوى بين الملل و توانمندى در اين زمينه ارتباط

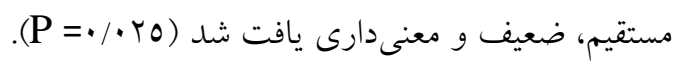

ارتباط متغييرهاى مورد مطالعه با مشخصات جمعيت

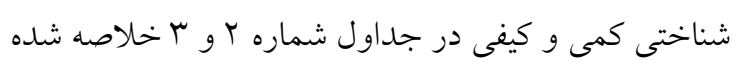

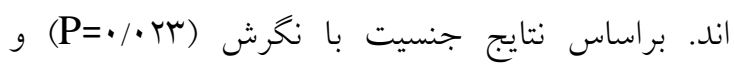

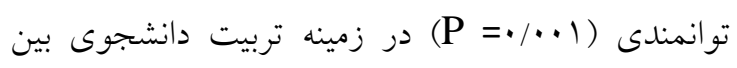

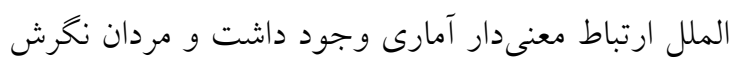
مثبت تر و توانمندى بيشترى در اين زمينه را ابزار نمودند.

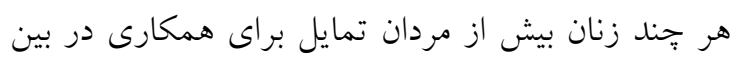

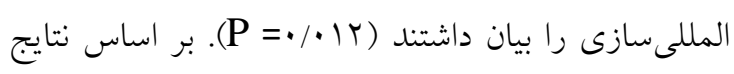
بين خروههاى مختلف تحصيلى از نظر نخرش تفاوت معنى

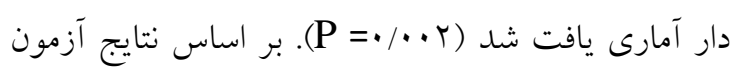
شفه، تفاوت گروههاى مختلف تحصيلى از نظر نخرش در ناري

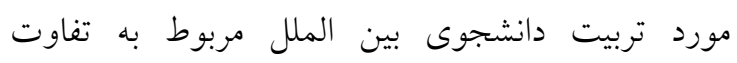

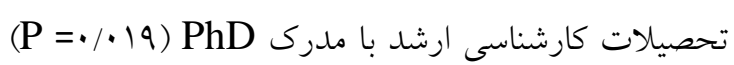

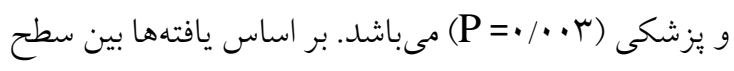

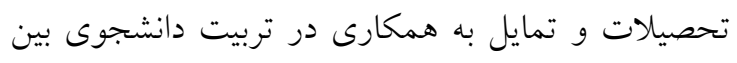

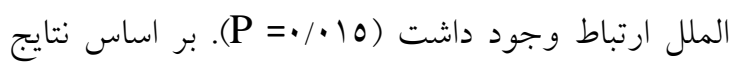
بين گروههاى مختلف رتبه علمى واحدهاى مورد بزّوهش

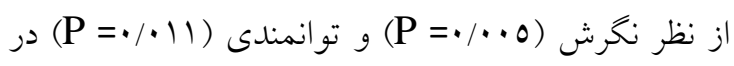
زمينه تربيت دانشجوى بين الملل تفاوت معنىدار وجود

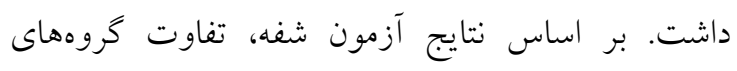

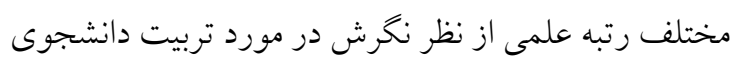
بين الملل مربوط به تفاوت رتبه مربى با رتبه استاد 
جدول شماره r: شاخصهاى عددى نغرش و توانمندى استادان در زمينه تربيت دانشجوى بين الملل برحسب سن، سابقه كار و سوابق

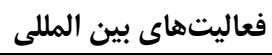

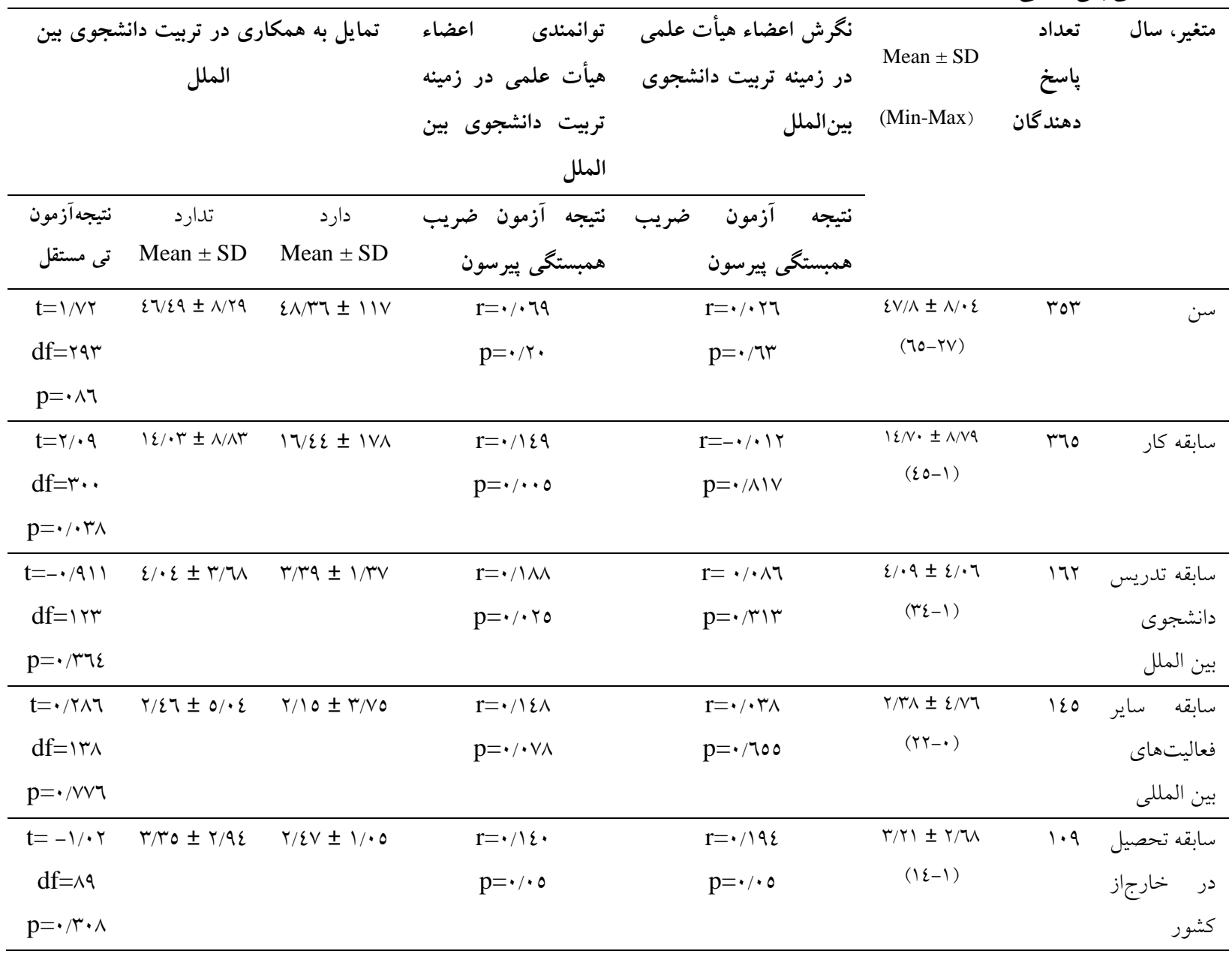

بر اساس نتايج، Vع/7 درصد شركت كنندگان (از الاس نفر

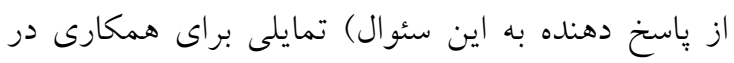

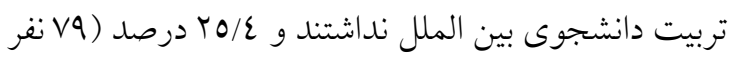

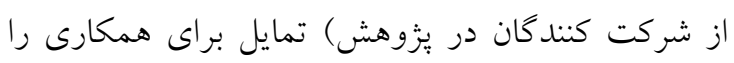

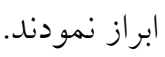

واحدهاى مورد يزوهش با سابقه مأموريت آموزشى يا

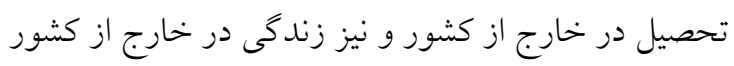

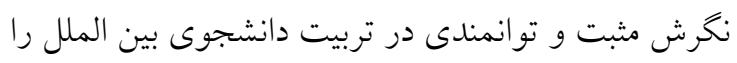

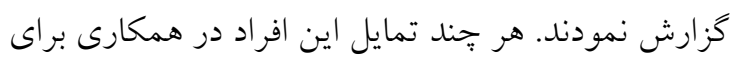
تربيت دانشجوى بين الملل كم بود. بين مدت زمان مان تحصيل

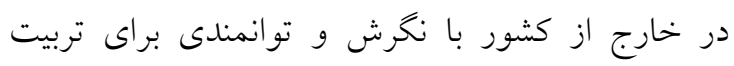
دانشجوى بين الملل و نيز تمايل براى تربيت دانشجوى بين ونسين الملل ارتباط معنى دارى وجود نداشت. بر اساس نتايج افراد

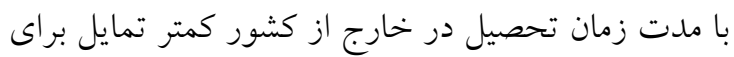
بيشترى براى همكارى در تربيت دانشجوى بين الملل

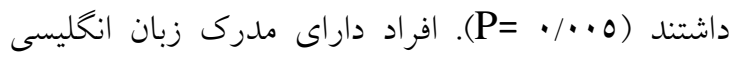
توانمندى بيشترى در تربيت دانشجوى بين الملل را ابراز داشتند (P =.r/. 
جدول شماره س: شاخص هاى عددى نغَرش و توانمندى استادان در زمينه تربيت دانشجوى بين الملل برحسب مشخصات جمعيت شناختى

\begin{tabular}{|c|c|c|c|c|c|c|c|c|c|c|}
\hline \multicolumn{3}{|c|}{ تمايل به همكارى در تربيت دانشجوى بين الملل } & \multicolumn{2}{|c|}{ توانمندى اعضاء هيات علمى در زمينه تربيت دانشجوى بين - } & \multicolumn{2}{|c|}{ نخرش اعضاء هيات علمى در زمينه تربيت دانشجوى بين - } & \multirow[t]{3}{*}{ ت تعداد (درصد) } & & \multirow[t]{3}{*}{ ت مهداد باسخ } & \multirow[t]{3}{*}{ 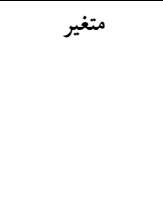 } \\
\hline \multirow[t]{2}{*}{ ن ن إيجه آزمون } & 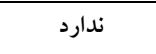 & دارد & نتيجه آزمون & Mean \pm SD & نتيجه آزمون & Mean \pm SD & & & & \\
\hline & تعداد (درصد) & تعداد (درصد) & & & & & & & & \\
\hline \multirow{2}{*}{$\begin{array}{c}\text { Chi-square }=r / r\urcorner \\
P=\cdot / \cdot 1 r\end{array}$} & $111(7 / / 0)$ & $01(r / / 0)$ & $\mathrm{t}=-r / r$ & $r Y / \varepsilon \wedge \pm \varepsilon / \wedge\rceil$ & $\mathrm{t}=-r / r q$ & Or/TY $\pm \Lambda / 71$ & $19 V(0 Y / 1)$ & زن & \multirow[b]{2}{*}{ rV } & 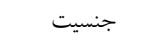 \\
\hline & $119(11 / \cdot)$ & $r \wedge(19 / \cdot)$ & $\begin{array}{c}\mathrm{df}=r \mathrm{r}) \\
P=. / . .1\end{array}$ & $r \varepsilon / T \varepsilon \pm 0 / r r$ & $\begin{array}{c}\mathrm{df}=r 09 \\
\mathrm{P}=\cdot / \cdot r r\end{array}$ & $\Delta \varepsilon / T V \pm \Lambda / r \varepsilon$ & $\operatorname{IVV}(\Sigma \mathrm{T} / \wedge)$ & مرد & & \\
\hline \multirow{3}{*}{$\mathrm{P}=. / \cdot 10$} & $9(\Sigma V / \varepsilon)$ & $1 \cdot(0 T / 7)$ & $F=1 / 17$ & $r \mid / 0 V \pm 0 / 1 \Lambda$ & $F=\varepsilon / 9 V$ & $\{V / \wedge 0 \pm 1 \cdot / N)$ & $T V(V / l \cdot)$ & كارشناسى ارشد & \multirow{3}{*}{$r \cdot o$} & ميزان تحصيلات \\
\hline & $1 \cdot 1(V V / 1)$ & $r r(r T / Q)$ & $\mathrm{df}=\mathrm{r}$ & $r H / \Lambda \Lambda \pm O / r r$ & $\mathrm{df}=r$ & $\Delta r / 21 \pm N / r$ & $\operatorname{lTV}(\varepsilon \varepsilon / T)$ & $\mathrm{PhD}$ & & \\
\hline & $\wedge(\wedge r / r)$ & $17(17 / \wedge)$ & $P=\cdot / 1$ ro & $r / \cdot \cdot \pm r / 0 r$ & $\mathrm{P}=\cdot / \cdot r$ & $0 \varepsilon / 7 \cdot \pm r / 71$ & $111(19 / \pi)$ & 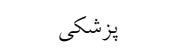 & & \\
\hline \multirow{4}{*}{$\mathrm{P}=\cdot / \cdot \bullet$} & $1 \cdot(\varepsilon \cdot / \cdot)$ & $10(7 . / \%)$ & \multirow{4}{*}{$\begin{array}{c}\mathrm{F}=r / N r \\
\mathrm{df}=r \\
\mathrm{P}=\cdot / \cdot / 1\end{array}$} & $r T / \cdot r \pm 0 / \varepsilon V$ & \multirow{4}{*}{$\begin{array}{c}\mathrm{F}=\varepsilon / \varepsilon r r \\
\mathrm{df}=r \\
\mathrm{P}=\cdot / . .0\end{array}$} & $\sum 9 / 2 \wedge \pm 9 / 10$ & ro $(9 / r)$ & 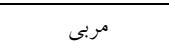 & \multirow{4}{*}{ r79 } & مرتبه علمى \\
\hline & $\ln (\mathrm{N} / \mathrm{N})$ & $r q(T Y / N)$ & & $r r / .1 \pm 0 / 11$ & & $O r / r r \pm N / A V$ & $r \cdot \varepsilon(0 \varepsilon / \cdot)$ & استاديار & & \\
\hline & $0 \cdot(v \cdot / \varepsilon)$ & $r I(T 9 / 7)$ & & $r r / \cdot . \pm 0 / \cdot \varepsilon$ & & $O r / 2 \wedge \pm \Lambda / T r$ & $\wedge \mathcal{E}(Y Y / Y)$ & دانشيار & & \\
\hline & $r \varepsilon(\Lambda q / 0)$ & $\varepsilon(1 \cdot / 0)$ & & $r 0 / 01 \pm 0 /$. & & $07 / 09 \pm 7 / 9 r$ & $\sum T(I T / T)$ & استاد & & \\
\hline \multirow{5}{*}{$\mathrm{P}=\cdot /|T|$} & $1 \wedge \Gamma(V Y / \Gamma)$ & $V \cdot(T V / N)$ & & YY/NG $\pm 0 / 17$ & & $O T / N \backslash \pm N / V \varepsilon$ & rII (AT/r) & عضو هيئت علمى & \multirow{5}{*}{ rvo } & بِست سازمانى \\
\hline & $11(9 \cdot / \cdot)$ & $r(1 / \cdot)$ & $\mathrm{F}=0 / \varepsilon \varepsilon$ & $r O / \Lambda \cdot \pm r / V_{0}$ & $F=r / \cdot V$ & $\Delta \tau / \cdot \varepsilon \pm N / 1 r$ & $Y I(0 / 7)$ & مدير كروه & & \\
\hline & $17(V V / r)$ & $0(T r / \Lambda)$ & $\mathrm{df}=\varepsilon$ & $r 7 / r 7 \pm \varepsilon / 79$ & $\mathrm{df}=\varepsilon$ & $0 \mathrm{~V} / \mathrm{T} \pm \mathrm{T} / 00$ & ro $(1 / 7)$ & معاون & & \\
\hline & $V(V / / \Lambda)$ & $r(T Y / Y)$ & $\mathrm{P}=\cdot / \cdot \cdot 1$ & rONO $\pm r / r \Lambda$ & $\mathrm{P}=\cdot / \wedge \wedge \varepsilon$ & $\Delta r / \bullet \wedge \pm T / \Delta \Lambda$ & $K(r / r)$ & رياست & & \\
\hline & $7(1 \ldots / \cdot)$ & $\cdot(\cdot /)$ & & $r \checkmark \cdot \cdot \pm 0 / q r$ & & Or/rE $\pm N / r_{0}$ & $7(1 / 7)$ & رئيس بخش & & \\
\hline \multirow{2}{*}{$\begin{array}{c}\text { chi-square }=\cdot / \pi r\urcorner \\
P=\cdot / 7\end{array}$} & $\operatorname{Tr}(\mathrm{VI} / \mathrm{V})$ & $\pi r(T r / \mu)$ & $t=-\varepsilon / 91$ & $r \varepsilon / 10 \pm 0 / 10$ & $t=-. / .01$ & or/rq $\pm q / \cdot 1$ & $17 T\left(\sum T / 9\right)$ & بله & \multirow[b]{2}{*}{$r v r$} & تربيت دانشجوى \\
\hline & $1.7(\mathrm{VI} / \mathrm{r})$ & 20 $(T r / N)$ & $\begin{array}{l}\mathrm{df}=\mathrm{rql} \\
\mathrm{P}<\bullet / .+1\end{array}$ & KY/YT $\pm \varepsilon / 10$ & $\begin{array}{l}\mathrm{df}=\mathrm{r} 01 \\
\mathrm{P}=\cdot / 97\end{array}$ & $\Delta r / r q \pm V / 9 q$ & rII (00/A) & خير & & بين الملل \\
\hline \multirow{3}{*}{$\begin{array}{c}\text { chi-square }=\Lambda / 79 \\
P=\cdot / . \bullet\end{array}$} & Vq $(79 / 9)$ & $1 r(r \cdot / 1)$ & $\mathrm{t}=-0 / \cdot \varepsilon$ & $r 0 / \varepsilon \cdot \pm \varepsilon / 9 \varepsilon$ & $\mathrm{t}=-r / \varepsilon \varepsilon$ & $00 / T r \pm v / r q$ & $1.9(\mathrm{rN/N})$ & بله & \multirow{3}{*}{$r v r$} & تحصيليا \\
\hline & $101(10 / 9)$ & $70(1 \varepsilon / 1)$ & $\mathrm{df}=\mathrm{r} 7 \mathrm{I}$ & YY/O. $\pm 0 / .1$ & $\mathrm{df}=\mathrm{roq}$ & $O Y / T V \pm N / \Lambda \varepsilon$ & $r 7 \varepsilon(79 / \Lambda)$ & & & ماموريتآموزشى \\
\hline & & & $\mathrm{P}<\cdot / \cdot \cdot \mathrm{P}$ & & $\mathrm{P}=. / \cdot \cdot 1$ & & & خير & & در خارج ازكشور \\
\hline \multirow{2}{*}{$\begin{array}{c}\text { chi-square }=1 \cdot / \wedge \wedge \\
P=\cdot / \cdot 1\end{array}$} & $91(71 / 2)$ & $\operatorname{IV}(r / / T)$ & $t=-\varepsilon / 99$ & $r O / 1 r \pm \varepsilon / 9 r$ & $\mathrm{t}=-r / \Lambda T$ & $00 / 0 \mathrm{~V} \pm \mathrm{V} / \mathrm{VT}$ & $r \sum 1(7 r / \Lambda)$ & بله & \multirow[b]{2}{*}{ rVT } & زندگى در خارج \\
\hline & $\operatorname{lrr}(\Lambda O / r)$ & $71(1 \varepsilon / \Lambda)$ & $\begin{array}{l}\mathrm{df}=r(\mathrm{rl} \\
\mathrm{P}<\cdot . . .1\end{array}$ & $r Y / r q \pm 0 / .0$ & $\begin{array}{l}\mathrm{df}=r \circ 9 \\
P<\cdot / . .1\end{array}$ & $01 / 99 \pm N / V V$ & $|r|(r \varepsilon / N)$ & خير & & از كشور \\
\hline \multirow{3}{*}{$\begin{array}{c}\text { chi-square }=\cdot / \cdot 0 \\
P=\cdot / \wedge 91\end{array}$} & $10 \cdot(\mathrm{NT/N})$ & $0 \cdot(T Y / T)$ & $t=-4 / r$ & $r r / \Lambda \varepsilon \pm 0 / .9$ & $t=-1 / N r$ & $o r / A V \pm N / 0$. & rro $(\pi / T)$ & بله & \multirow{3}{*}{ rvi } & داشتن مدرى \\
\hline & $v_{a}\left(v_{0} / \cdot\right)$ & TA (TO/.) & $d f=r o 9$ & $r Y / 00 \pm 0 / 1 \Lambda$ & $d f=r o v$ & Or/YE $\pm N / 77$ & $1 \pi\rceil(r \rrbracket / \cdot)$ & خير & & زبان انحُليسى \\
\hline & & & $\mathrm{P}=\cdot / \cdot \mathrm{r}$ & & $P=\bullet / \wedge \varepsilon$ & & & & & \\
\hline
\end{tabular}


اى، گروه آموزشى، دانشخاهى و كشورى دسته بندى شدند. بر اساس نتايج، از ع|| شركت كننده حدود 10 درصد در يزوهش كمبود زيرساخت ها و نبودن بستر مناسب و كمبود امكانات و تجهيزات در دانشخاه و كروههاى آموزشى براى تربيت دانشجوى خارجى را به عنوان علت نداشتن تمايل براى همكارى بيان نمودند.
در جدول شماره ع علل مرتبط با تمايل يا عدم تمايل به همكارى در تربيت دانشجوى بين الملل كه توسط عال النق از شركت كنندگان در يزٔوهش بيان شده است، ارائه مى هـ كردد. علل مرتبط با نداشتن تمايل به همكارى در دو طبقه فردى و دانشخاهى و از علل مرتبط با تمايل به همكارى در تربيت دانشجوى بين الملل به جهار دسته فردى و حرفه

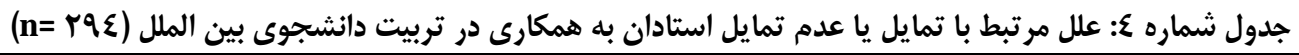

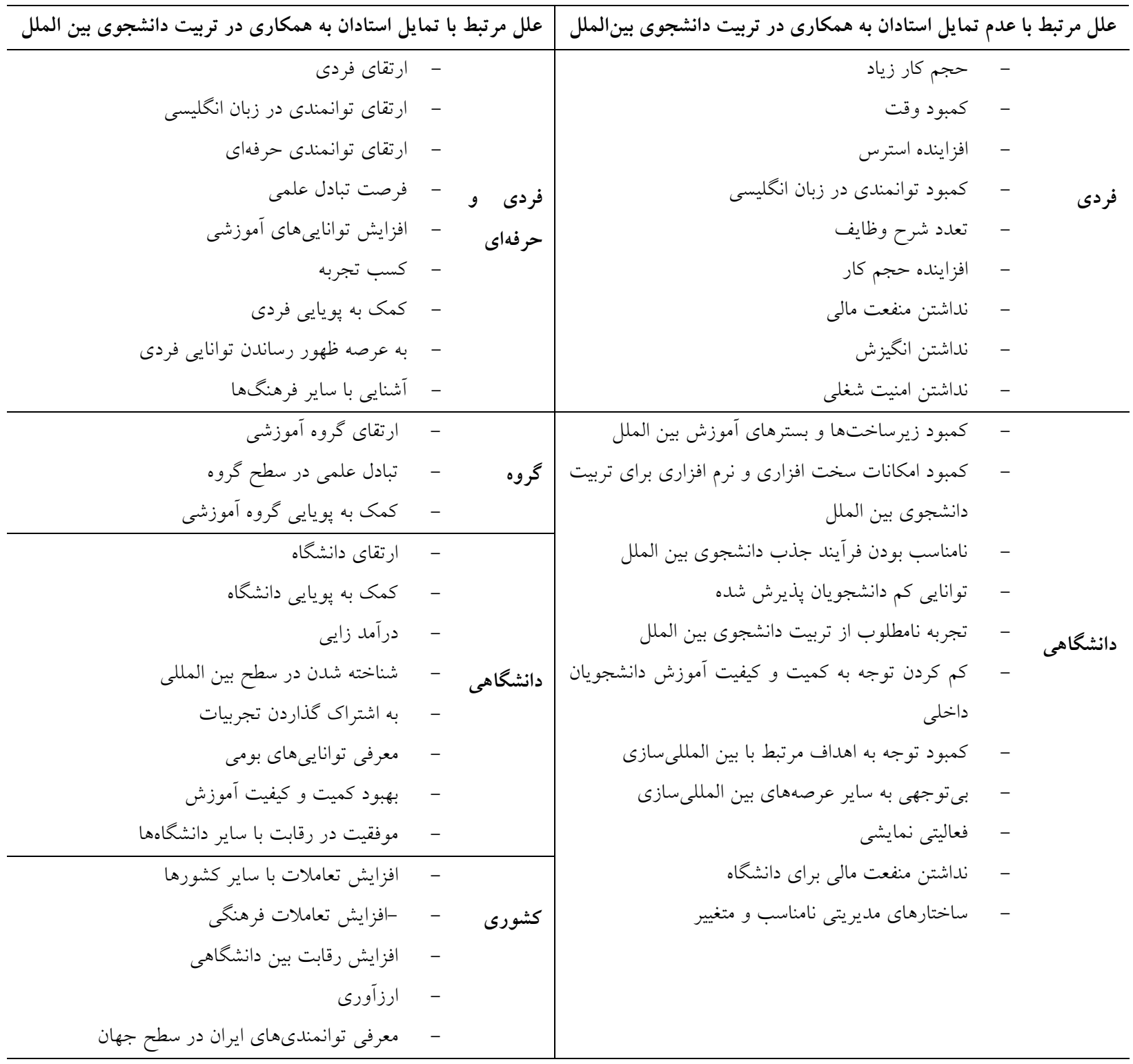

دانشجوى بين الملل نداشتند. درى و باور از توانايى يا

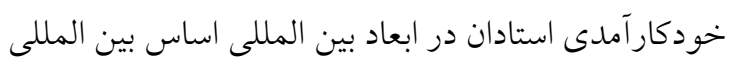

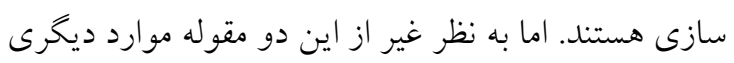

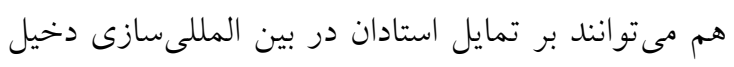

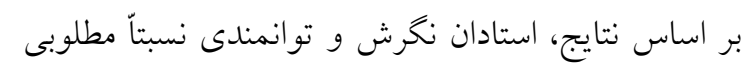

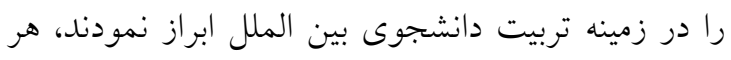

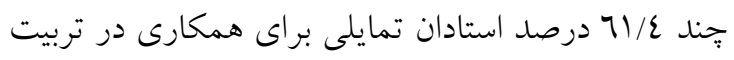


داراى مدرى زبان انخليسى توانمندى بيشترى در تربيت

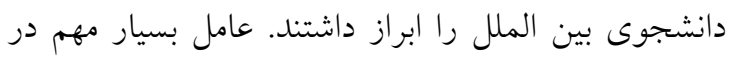

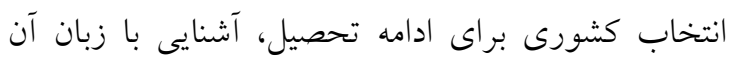

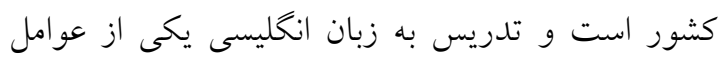

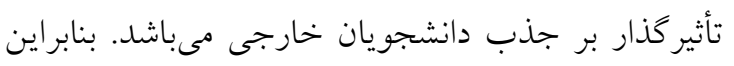

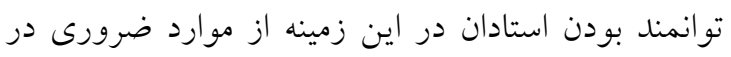
فرآيند بين المللى سازى است.

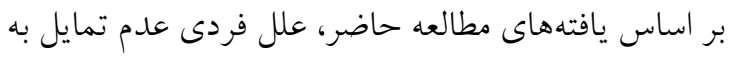
همكارى در تربيت دانشجوى خارجى نداشتن منفعت مالى، انخيزش و امنيت شغلى، كمبود توانمندى در زبان

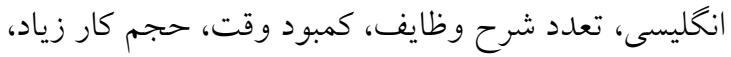
و تربيت دانشجوى خارجى به عنوان افزاينده حجم كار و استرس بودند. استادان عوامل اصلى در نهادينه نمودن

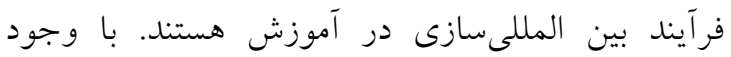
كسترش متون در زمينه بين المللىسازى، مطالعات كمى بـى درى درك و نخرش استادان در خصوص نقششان در اين فرآيند

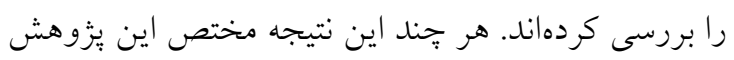

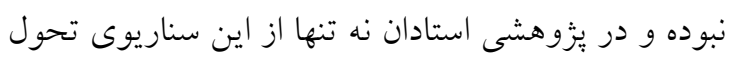

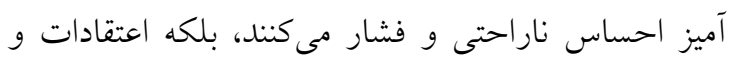

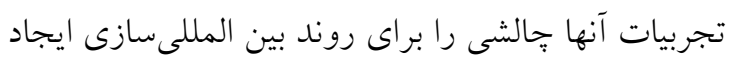

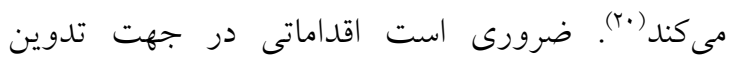
راهبردهايى براى همراه نمودن استادان به عنوان بازيخران

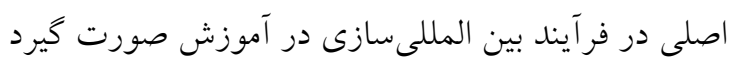
تا دركيرى اين عوامل كليدى در اين فرآيند افزايش يابد. از طرفى انخيزشهاى محيطى يا سازمانى مىتواند انخيزش

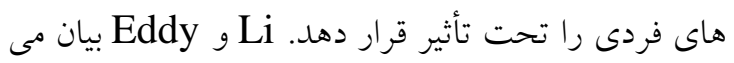
كنند كه بستر اجتماعى مىتواند تسهيل كننده مشاركت استادان در عرصه بين الملل براى منفعت فردى او باشد و

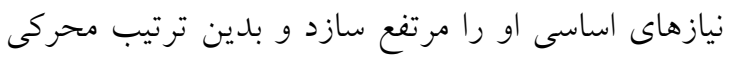
براى انخيزش فردى در فعاليت بين المللى فراهم نمايد.

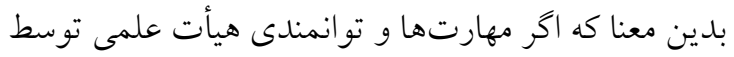
سازمان افزايش يابد مشاركت او در عرصه بين الملل بيشتر خواهد بود. انخيزش در بركيرنده ادراكات عضو هيئت

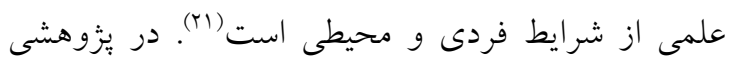

باشند. استادانى كه خود را با صلاحيت در تعاملات بين المللى درك نمودهاند، از مشاركت كنندكان فعال در تربيت بـاني

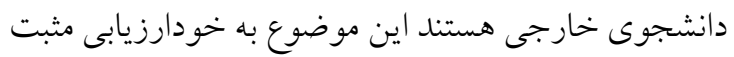

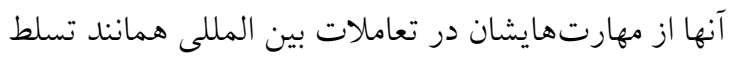
بر زبان، و درك ساير فرهنگها مرتبط است (10). بر اساس نتايج مردان نخرش مثبت وتر و توانمندى بيشترى در زمينه تربيت دانشجوى خارجى ابزار نمودند. هر خند

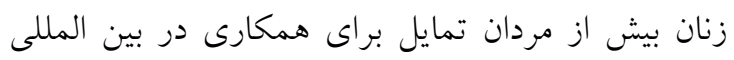

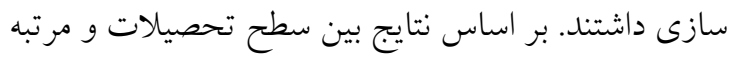
علمى با تمايل براى همكارى در تربيت دانشجوى بين لترائ الملل ارتباط وجود داشت. Jin and Schneider نشان بهان دادند كه زمينه استادان مىتواند بر باور آنها درباره دانشجويان بين الملل اثر كذار باشد و بين نخرش اعضاء و

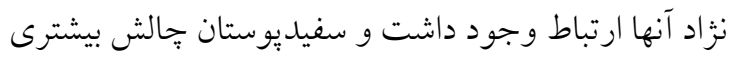
همانند زبان را در آموزش دانشجويان خارجى بيان نمودند و نيز بين نكرش اعضاء با دانشكده و رشته تحصيليشان

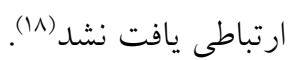
يافتهاى يزّوهش حاضر نشان داد افر اد با سابقه كار بيشتر تمايل در همكارى براى تربيت دانشجوى بين الملل داشتند. در اين يزوهش تنها يك سئوال در بررسى تمايل

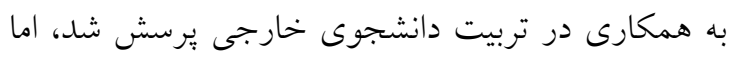

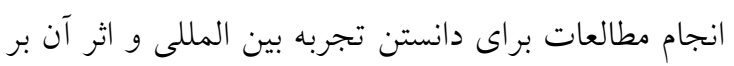

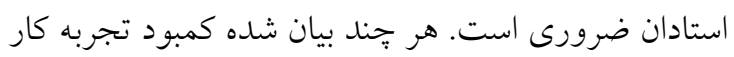

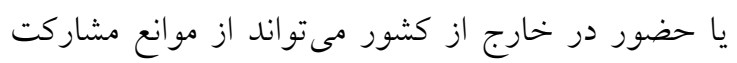

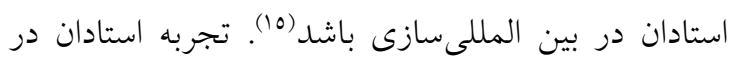

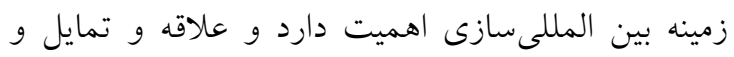
مشاركت اعضاء براى موفقيت تلاشهاى بين المللىسازى

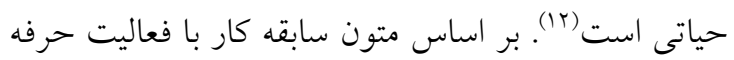

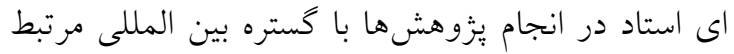
است و استادان با سابقه بيشتر در مقايسه با افراد با سابقه

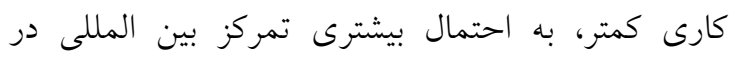

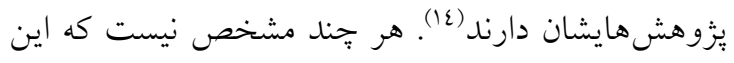

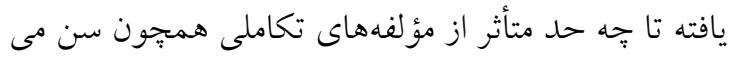

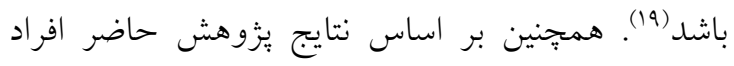


دانشجوى بين الملل، نامناسب بودن فرآيند جذب

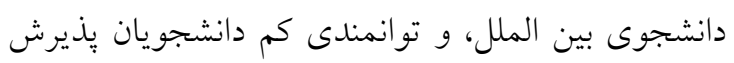

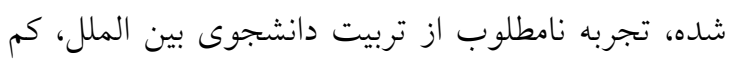

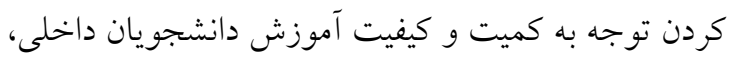

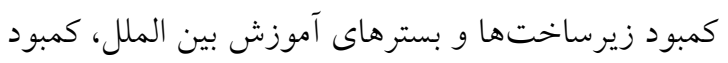

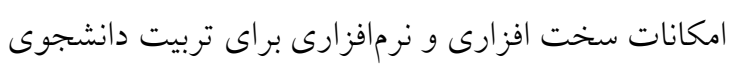

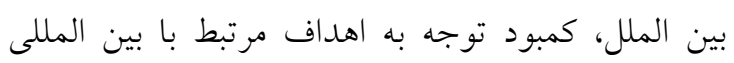

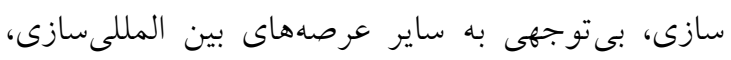

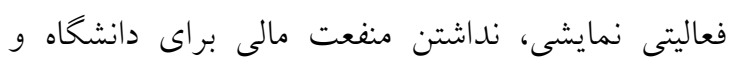

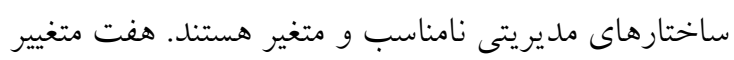

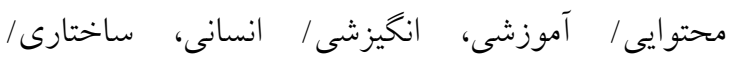

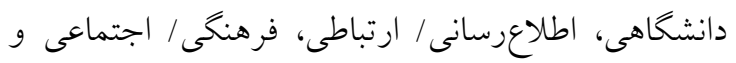

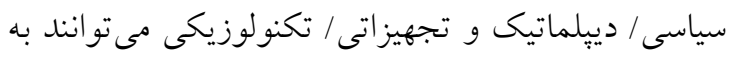

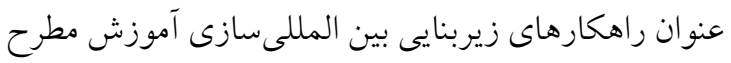

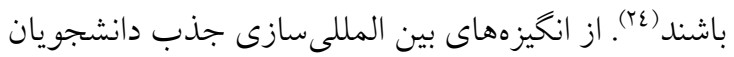

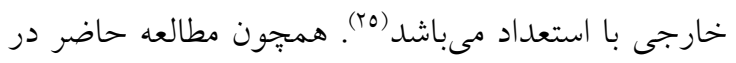

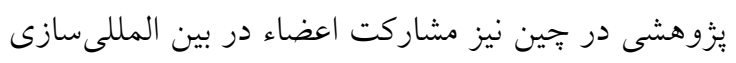

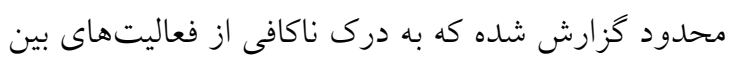

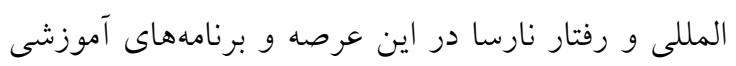

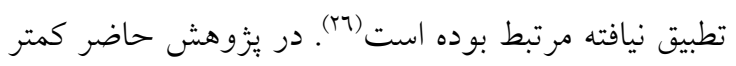

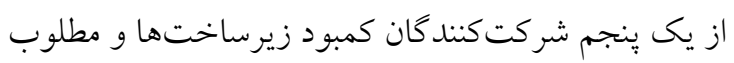

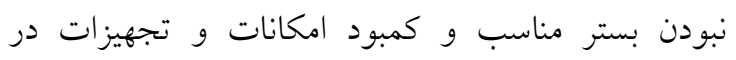

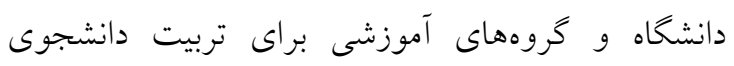
خارجى را به عنوان علت نداشتن تمايل براى همكارى بيان

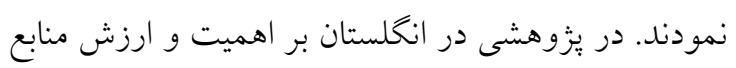

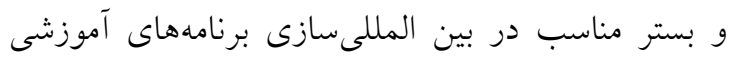
تأكيد كردند

در يُزوهش حاضر علل فردى تمايل به همكارى در تربيت

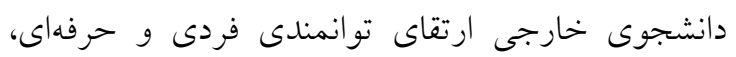

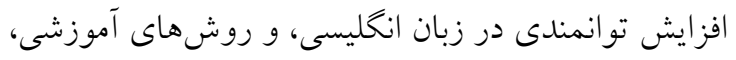

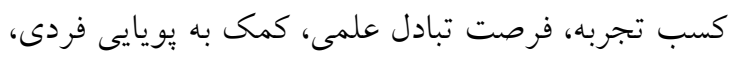

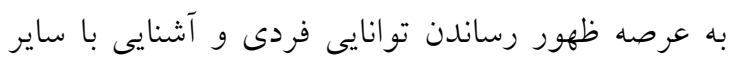

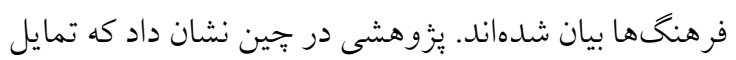

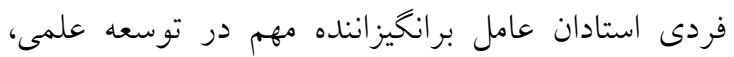

درى استادان از انخيزشهاى محيطى هماند حقوق، خط مشى ارتقاء و فرهنگ سازمانى شكل دهنده رفتار استادان

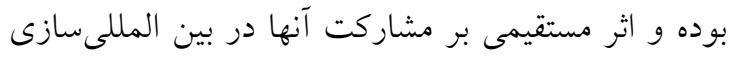

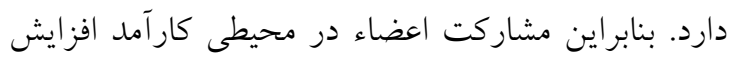

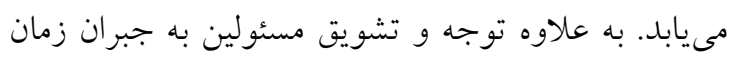

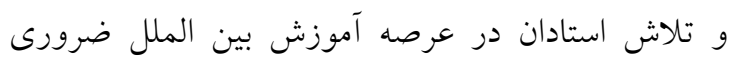

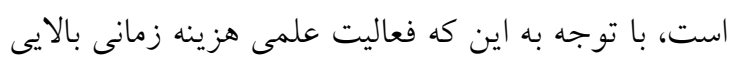

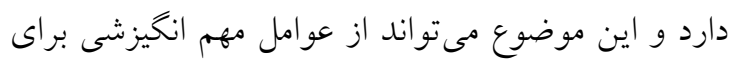
استادان باشد (10).

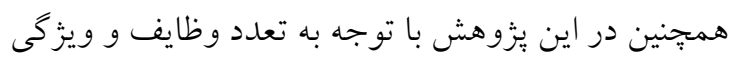

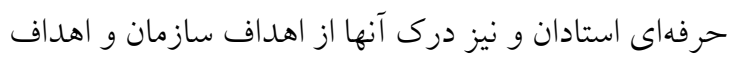
بين المللى شدن دانشخاه شرايط همكارى در عرصه بين الملل براى تربيت دانشجوى خارجى فراهم نيست. رفتار

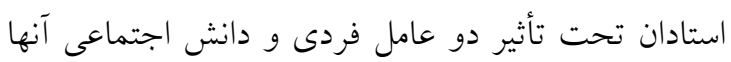

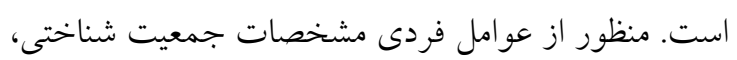

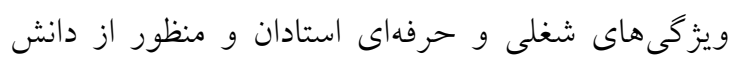

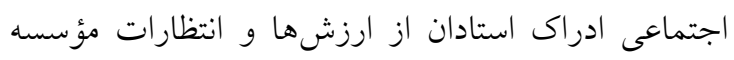

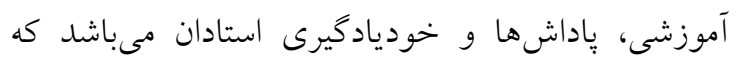
شكل دهنده رفتار عضو هيأت علمى هستند (YT) بادئ.

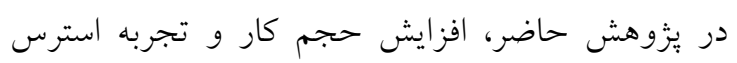

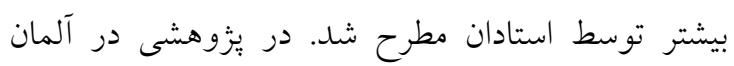

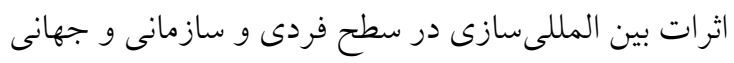
كزارش شدند. در سطح فردى به بين المللى سازى به عنوان

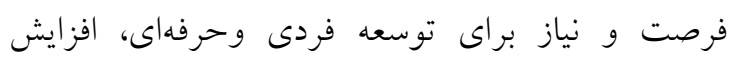
باركارى و استرس، و سرآمدى بين المللى اشاره شد (rr).

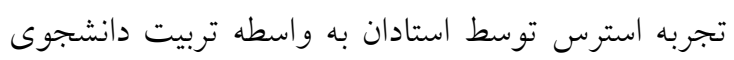

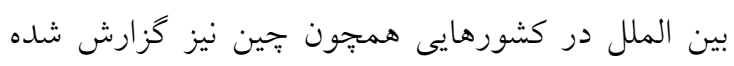

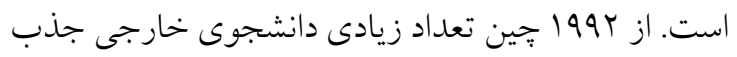

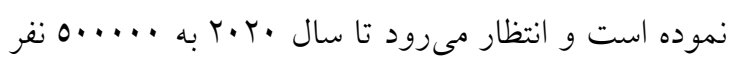

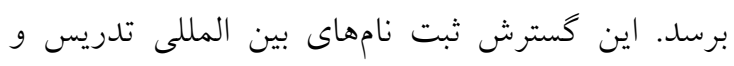

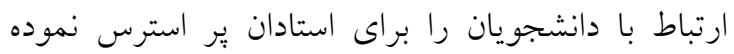

(10)

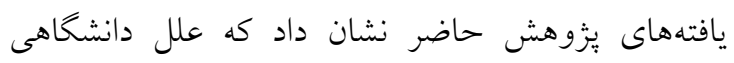

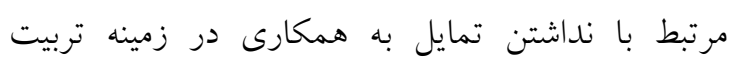


اين كشور با كمبود بودجههاى توسعهاى مواجه

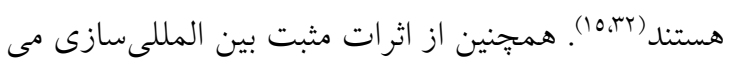

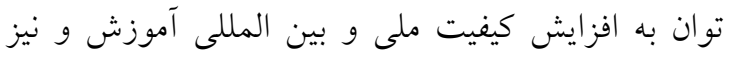

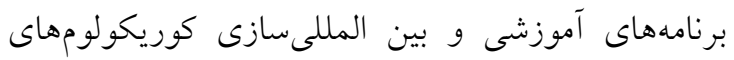

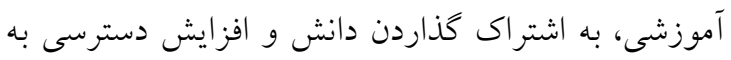
دانش، يُزوهش و اطلاعات علمى اشاره كرد (ب0) كه اينها خود مىتو انند بسترى براى فعاليتهاى بين المللى فراهم

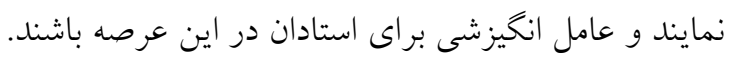

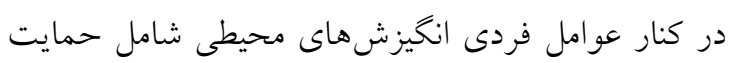

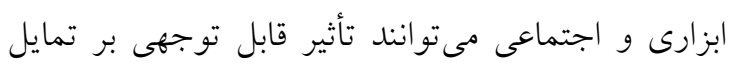

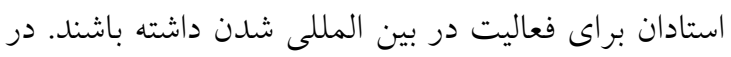

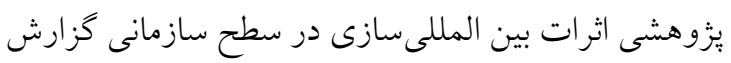

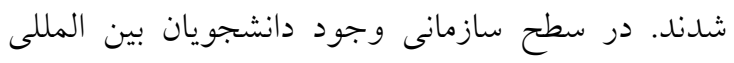

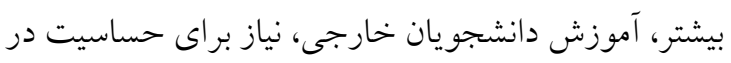

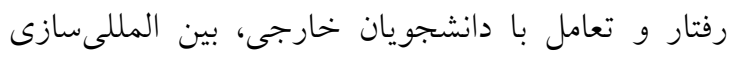

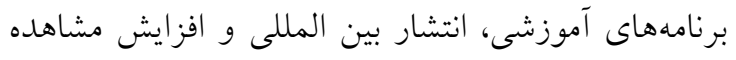

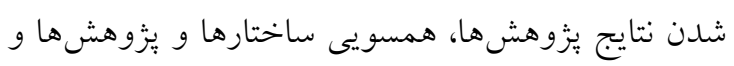

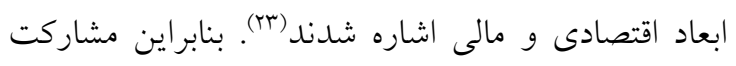

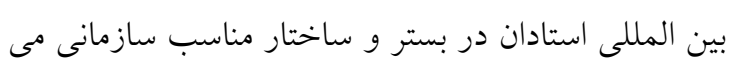
تواند افزايش يابد (Tr). در اين يزّوهش از جمله علل كشورى تمايل به همكارى در تربيت دانشجوى خارجى افزايش تعاملات با ساير كشورها، افزايش تعاملات فرهنكى، افزايش رقابت بين

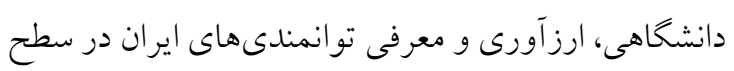

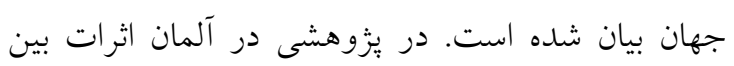

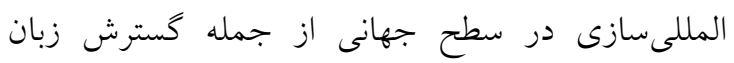

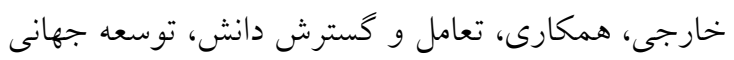

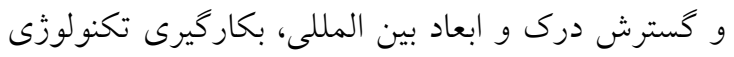

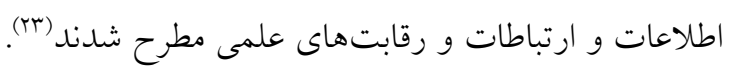

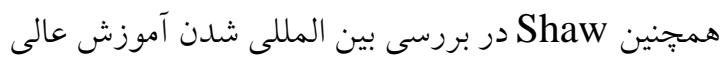

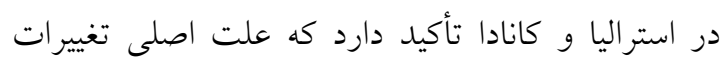

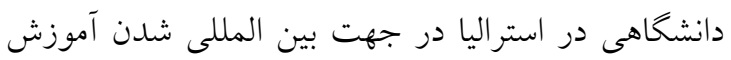
عالى، كمى به اقتصاد آن كشور است (گَ).

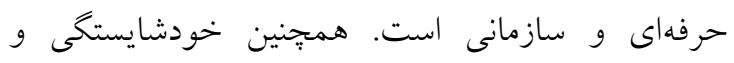

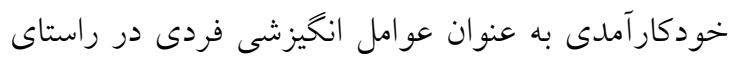

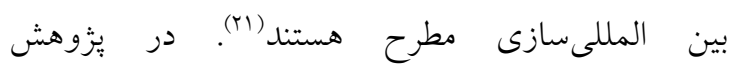

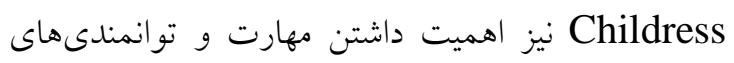
فردى براى انجام فعاليتهاى بين المللى مورد تأكيد قرار

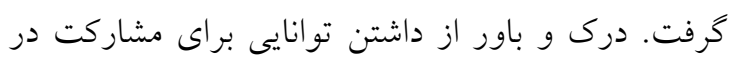

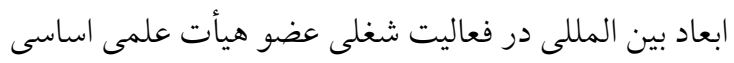

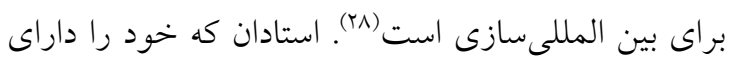

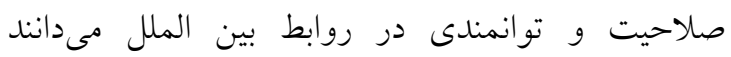
مشاركت كنندگان فعال در عرصه بين المللىسازى هستند.

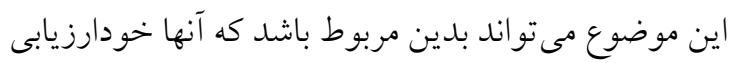

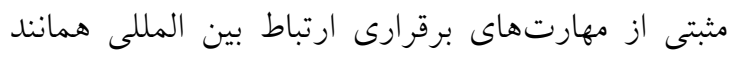

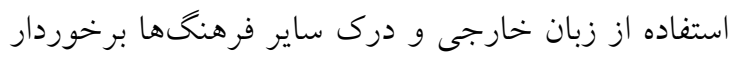

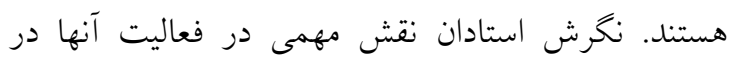

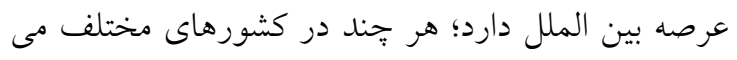

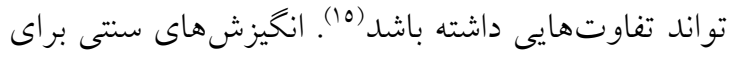

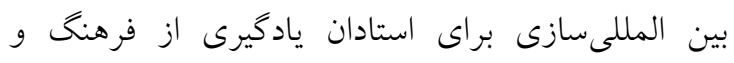

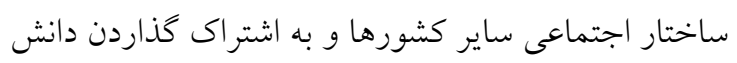
بيان شده است (T0) از جمله علل دانشگاهى تمايل به همكارى در تربيت

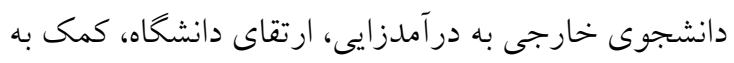

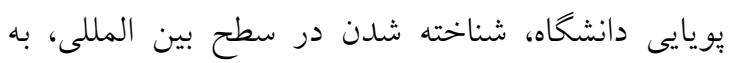

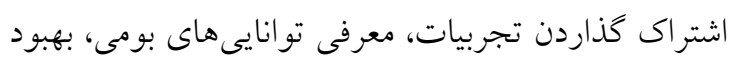

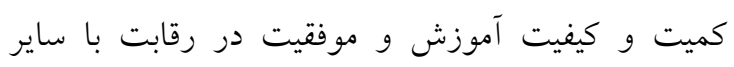

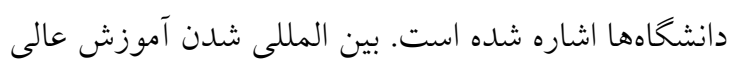

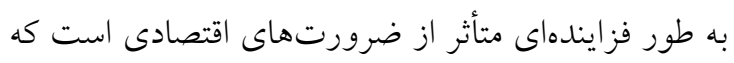

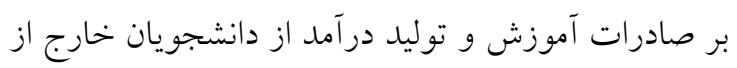

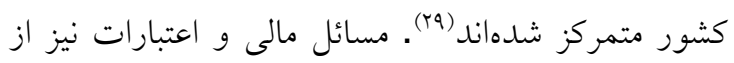
جمله عوامل مهم در فعاليتهاى بين المللى است. براى مدرد

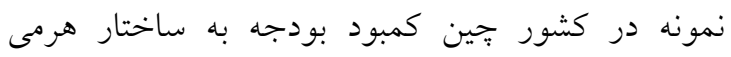

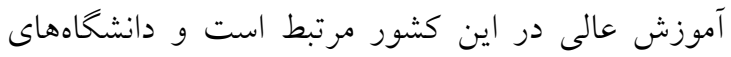

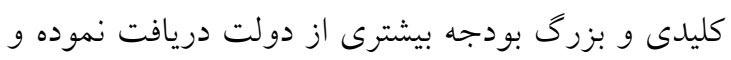

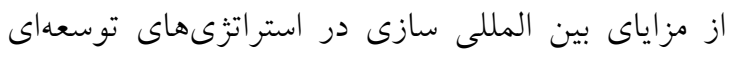

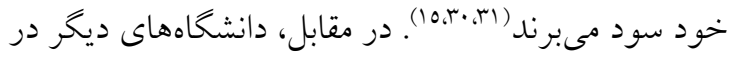


اركان بين المللىسازى هدايت نمايند. در راستاى رشد و

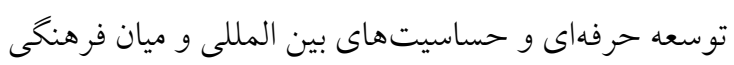

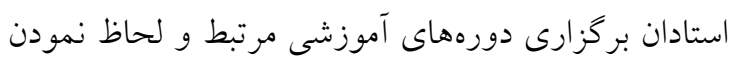

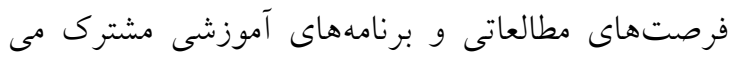
توانند به توسعه دانش، تجربه و نغرش بين المللى استادان كمى كند و نياز است اين موضوع مورد توجه مسئولين در

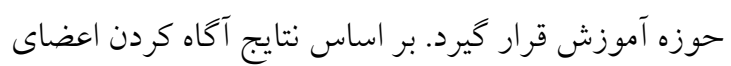

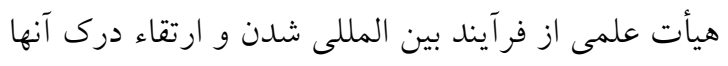
نسبت به اثرات بين المللى شدن نه تنها بر كيفيت كوشش ونش

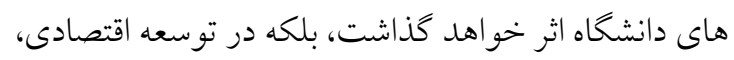
اجتماعى و فرهنكى جامعه زير يوشش دانشخاه نيز مى تواند

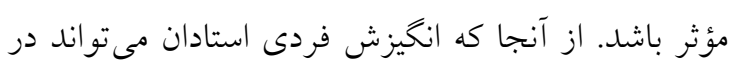

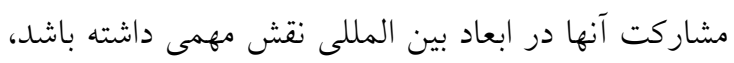
براى مشاركت اعضاء در عرصههاى بين المللى بايد انرزى داري

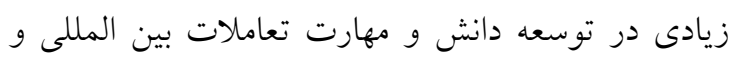

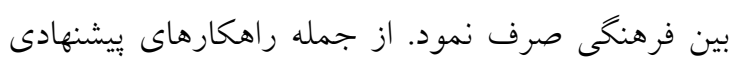

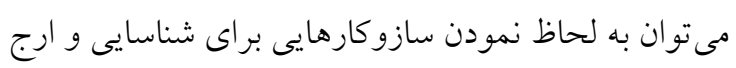
نهادن به بهترين تلاشها در عرصه بين الملل توسط استادان

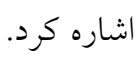

تعارض منافع: هيج گونه تعارض منافع از سوى نويسندگان كزارش نشده است.

\section{تقدير و تشكر}

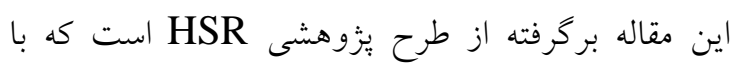
حمايت مالى معاونت آموزشى دانشعاه علوم يزشكى ايران

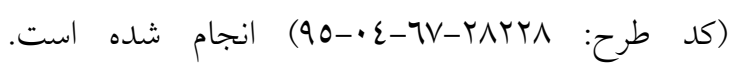

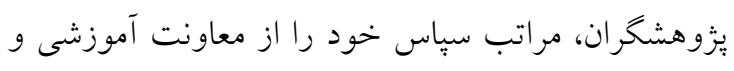

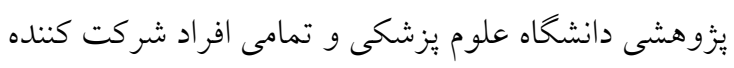
در تحقيق را اعلام مىدارند.
استادان محور فر آيندهاى علمى همجيون بين المللىسازى

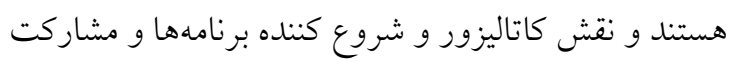

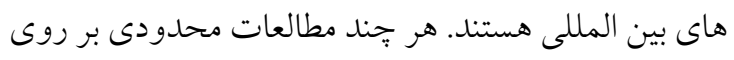
استادان و مشاركت آنها در بين المللى سازى صورت كر مرفته

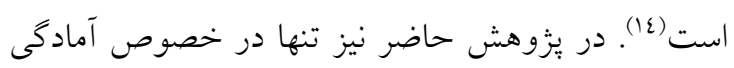
استادان كروههاى آموزشى در تربيت دانشجوى بين الملل

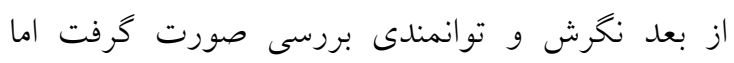

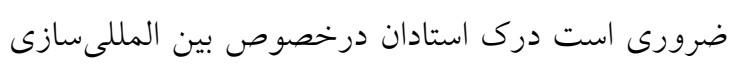

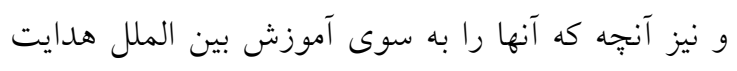

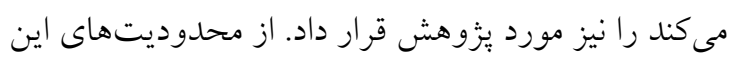

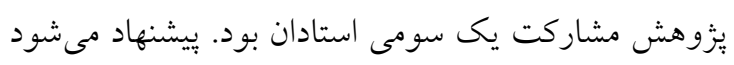
مطالعات كيفى با هدف تبيين فرايند مشاركت استادان و نيز

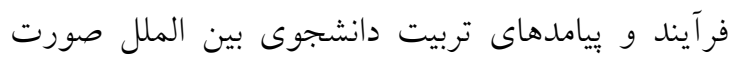
كيرد. ضرورى است براى توسعه ابعاد بين المللى دانشكاه نيز جشم انداز و برنامه هاى راهبردى مجز ايى تدوين شودي

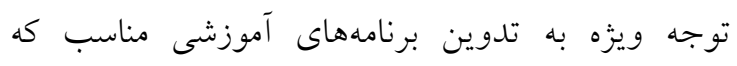

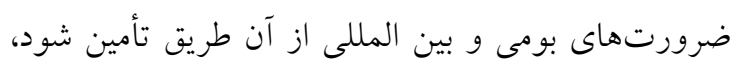

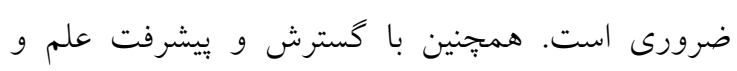

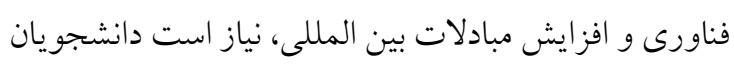

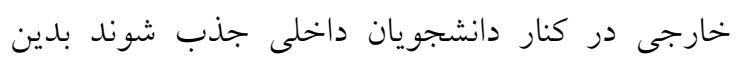
ترتيب گامى در جهت تربيت نيروى كار توانا در انجام

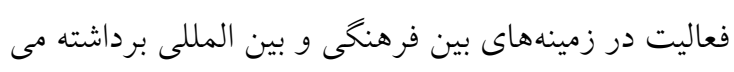

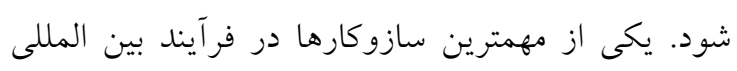

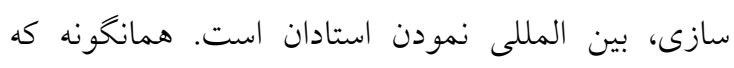

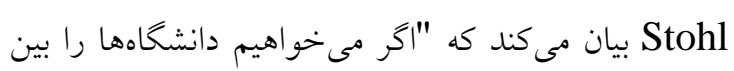

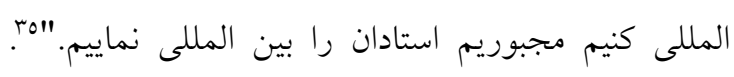

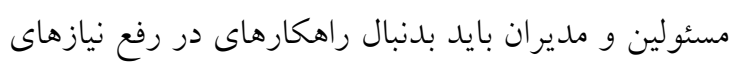

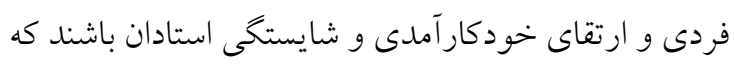

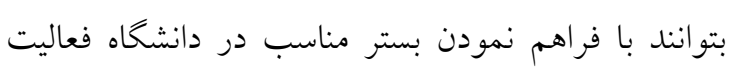

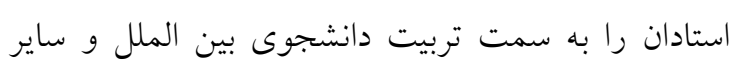

\section{References}


1. Mariani AW, Pêgo-Fernandes PM, Samano MN. Internationalization of universities: the need to navigate in foreign waters. Sao Paulo Med J. 2013;131(1):3-4.

2. Knight J. Internationalization of higher education: A conceptual framework. Internationalisation of higher education in Asia Pacific countries. 1997:5-19.

3. Altbach PG, Knight J. The internationalization of higher education: Motivations and realities. $J$ Stud Int Educ. 2007;11(3-4):290-305.

4. De Wit H. Internationalization of higher education in the United States of America and Europe: A historical, comparative, and conceptual analysis. Greenwood Publishing Group; 2002.

5. Jackson MG. Internationalising the university curriculum. Journal of Geography in Higher Education. 2003;27(3):325-40.

6. Cotton DR, Morrison D, Magne P, Payne S, Heffernan T. Global Citizenship and Cross-Cultural Competency: Student and Expert Understandings of Internationalization Terminology. J Stud Int Educ. 2019;23(3):346-64.

7. Slaughter S, Leslie LL. Expanding and elaborating the concept of academic capitalism. Organization. 2001;8(2):154-61.

8. Marmolejo F. Internationalization of higher education: the good, the bad, and the unexpected. Chron High Educ. 2010 Oct;22.

9. Hénard F, Diamond L, Roseveare D. Approaches to internationalisation and their implications for strategic management and institutional practice. IMHE Institutional Management in Higher Education. Accessed on [http://www. oecd. org/edu/imhe/Approaches\% 20to\% 20internationalisation\% 20-\% 20final\% 20-\% 20web. pdf]. 2012;11(12):2013.

10. Evans $\mathrm{C}$. The experience of international doctoral education in nursing: An exploratory survey of staff and international nursing students in a British university. Nurse Educ Today. 2007;27(5):499505.

11. Ryan JM. A guide to teaching international students. Oxford Centre for Staff and Learning Development; 2000.

12. Friesen R. Faculty member engagement in Canadian university internationalization: A consideration of understanding, motivations and rationales. J Stud Int Educ. 2013;17(3):209-27.

13. Schwietz MS. Internationalization of the academic profession: An exploratory study of faculty attitudes, beliefs and involvement at public universities in Pennsylvania (Doctoral dissertation, University of Pittsburgh).

14. Finkelstein MJ, Walker E, Chen R. The American faculty in an age of globalization: Predictors of internationalization of research content and professional networks. Higher Education. 2013;66(3):325-40.

15. Li B, Tu Y. Motivations of faculty engagement in internationalization: a survey in China. Higher Education. 2016;71(1):81-96.

16. Hardré PL, Beesley AD, Miller RL, Pace TM. Faculty Motivation to do Research: Across Disciplines in Research-Extensive Universities. Journal of the Professoriate. 2011;5(1) 35-69.

17. Bazargan A, Fashalanj L. The process of internationalization of universities: a case of higher education in Iran. New Thoughts on Education: Faculty of Education and Psychology. 2016; 11(4): 9-37. [Persian]

18. Jin L, Schneider J. Faculty views on international students: A survey study. Journal of International Students. 2019;9(1):84-99.

19. Baldwin RG, Blackburn RT. The academic career as a developmental process: Implications for higher education. The Journal of Higher Education. 1981;52(6):598-614.

20. Heringer R. 'It'sa lot of homework for me': post-secondary teachers' perception of international students and internationalization in Canada. Teaching in Higher Education. 2019 13:1-6. 
21. Eddy PL, Li B. The role of e-learning for faculty development in China. The New Educational Review. 2014;35(1):88.

22. Blackburn RT, Lawrence JH. Faculty at work: Motivation, expectation, satisfaction. Johns Hopkins University Press; 1995.

23. Bedenlier S, Kondakci Y, Zawacki-Richter O. Two decades of research into the internationalization of higher education: Major themes in the Journal of Studies in International Education (1997-2016). J Stud Int Educ. 2018;22(2):108-35.

24. Zamani Manesh H, Khorasani A, Youzbashi A. Effective Ways in Internationalizing the Curricula of Medical Sciences: Viewpoints of Faculty Members in Shahid Beheshti University of Medical Sciences. Iranian Journal of Medical Education. 2013;13(4):291-305. [Persian]

25. Yesufu LO. Motives and Measures of Higher Education Internationalisation: A Case Study of a Canadian University. International Journal of Higher Education. 2018;7(2):155-68.

26. Li BH, Tu YJ. Faculty's limited engagement in higher education internationalization. InFudan Education Forum 2012;10(6): 54-8.

27. McKinnon S, Hammond A, Foster M. Reflecting on the value of resources for internationalising the curriculum: exploring academic perspectives. J Furth High Educ. 2019;43(1):138-47.

28. Childress LK. The twenty-first century university: Developing faculty engagement in internationalization. Peter Lang; 2010.

29. Jiang X. Towards the internationalisation of higher education from a critical perspective. $J$ Furth High Educ. 2008;32(4):347-58.

30. Yuan B. Internationalization at home: The path to internationalization in Chinese research universities. Chinese Education and Society. 2011;44(5):84-96.

31. Gao Y. Constructing internationalisation in flagship universities from the policy-maker's perspective. Higher Education. 2015;70(3):359-73.

32. Yang R. Progress and paradoxes: New developments in China's higher education. InCentralization and decentralization 2004 (pp. 173-200). Springer, Dordrecht.

33. Knight J. Internationalization remodeled: Definition, approaches, and rationales. J Stud Int Educ. 2004;8(1):5-31.

34. Shaw K. Internationalization in Australia and Canada: Lessons for the Future. College Quarterly. 2014;17(1):n1.

35. Stohl M. We have met the enemy and he is us: The role of the faculty in the internationalization of higher education in the coming decade. J Stud Int Educ. 2007;11(3-4):359-72. 